\title{
Eliciting Public Attitudes Regarding Bioremediation Cleanup Technologies: Lessons Learned from a Consensus Workshop in Idaho
}
A Report Presented to the U.S. Department of
Oregon State University

March 2003 
Eliciting Public Attitudes Regarding Bioremediation Cleanup Technologies: Lessons Learned from a Consensus Workshop in Idaho

\section{Table of Contents}

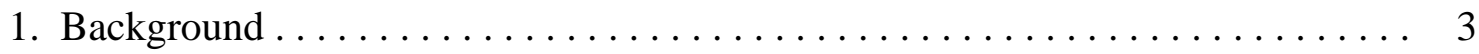

2. The Idaho Consensus Workshop $\ldots \ldots \ldots \ldots \ldots \ldots \ldots \ldots \ldots \ldots \ldots \ldots$

3. Lessons Learned: Participants Concerns about

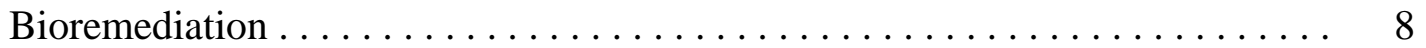

4. Lessons Learned: Materials and Delivery Methods

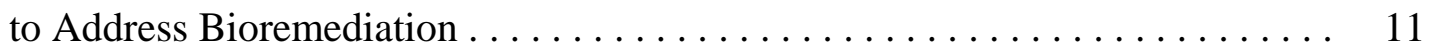

5. Lessons Learned: Effectiveness of the Consensus Workshop

for Involving the Public in a Dialogue about Bioremediation . . . . . . . . . 15

6. Conclusions ............................... 19

7. References Cited . . . . . . . . . . . . . . . . . . . . 19

Appendix A. Manual for Conducting a Consensus Workshop . . . . . . . . . . . 21

Appendix B. Introduction to Bioremediation at DOE Sites . . . . . . . . . 37

Appendix C. Bioremediation Questions and Concerns Identified by

Advisory Committee Members . . . . . . . . . . . . . . 60

Appendix D. Working Script for Workshop Session . . . . . . . . . . . 62

Appendix E. List of Experts Participating in Consensus Workshop . . . . . . . . . 65

Appendix F. Bioremediation as a Remediation Technology

A Consensus Report From A Citizen Panel To

The Department Of Energy .................. 66 


\section{Background}

During the summer of 2002, we developed and implemented a "consensus workshop" with Idaho citizens to elicit their concerns and issues regarding the use of bioremediation as a cleanup technology for radioactive nuclides and heavy metals at Department of Energy (DOE) sites. The consensus workshop is a derivation of a technology assessment method designed to ensure dialogue between experts and lay people. It has its origins in the United States in the form of "consensus development conferences" used by the National Institutes of Health (NIH) to elicit professional knowledge and concerns about new medical treatments. Over the last 25 years, NIH has conducted over 100 consensus development conferences. (Jorgensen 1995).

Beginning in the 1980s, the Danish Technology Board began using the consensus development conference approach to facilitate public debate about developments in science and technology. With an interest in involving lay people as well as scientists and special interest groups, they expanded the model to include a panel of lay people in the design. Other countries, such as the United Kingdom and the Netherlands, have used the model developed in Denmark (Joss and Durant 1995).

The consensus conference is grounded in the idea that technology assessment and policy needs to be socially negotiated among many different stakeholders and groups rather than narrowly defined by a group of experts. To successfully implement new technology, the public requires access to information that addresses a full complement of issues including understanding the organization proposing the technology. The consensus conference method creates an informed dialogue, making technology understandable to the general public and sets it within perspectives and priorities that may differ radically from those of the expert community. While specific outcomes differ depending on the overall context of a conference, one expected outcome is that citizen panel members develop greater knowledge of the technology during the conference process and, sometimes, the entire panel experiences a change in attitude toward the technology and/or the organization proposing its use (Kluver 1995).

While all methods of public participation have strengths and weaknesses, the consensus conference ranks high on effectiveness in areas that are of interest at DOE sites (Rowe and Frewer 2000). Specifically, the consensus conference is an effective process for identifying the variety and complexity of attitudes held by the general public regarding bioremediation and creating an understanding that is likely to lead to acceptance of technology strategies. Strengths inherent to the consensus conference include a high degree of participant independence, early participant involvement, transparency of the process to the public, public resource accessibility, clear task definition, and costeffectiveness. The consensus conference method of defining public concerns also avoids some of the weaknesses of the survey method, especially the tendency for surveys to assume a monolithic general public that is deficient in its understanding of science (Davison et al, 1997). The consensus conference establishes a forum for interactive public consultation and it elicits a more considered range of public concerns. 
Importantly with regard to INEEL and other DOE sites, the consensus conference method has strengths that the "citizens advisory committee" method of public participation does not. The consensus conference supports independence of the participants from the institutions or individuals using or promoting a certain technology or approach, greater transparency of the discussion and recommendation process, greater access to resources, and cost effectiveness (Rowe and Frewer 2000). Also, the consensus conference provides a relatively short-term, finite method for involving the public, which results in a written report of the public issues identified in the process. Limitations of the method, however, include a smaller degree of representativeness than a survey provides and less structuring of the decision-making to the extent that would occur in an approach like a citizen’s jury/panel.

The purpose of this research project was to explore the efficacy of the consensus conference model as a way to elicit the input of the general public about bioremediation of radionuclides and heavy metals at Department of Energy sites. Objectives of the research included:

(1) defining the range of concerns of the public toward different bioremediation strategies and long-term stewardship;

(2) creating materials and delivery methods that address bioremediation issues; and

(3) assessing the effectiveness of the consensus workshop in identifying concerns about bioremediation and involving the public in a dialogue about their use.

After a brief description of the Idaho workshop, we discuss the range of concerns articulated by the participants about bioremediation, discuss the materials and delivery methods used to communicate information about bioremediation, and assess the effectiveness of the consensus workshop. In summary we found that panel members in general:

- understood complex technical issues, especially when given enough time in a facilitated discussion with experts.

- $\quad$ are generally accepting of in situ bioremediation, but concerned about costs, safety, and effectiveness of the technology.

- $\quad$ are concerned equally about technology and decision processes.

- liked the consensus workshop approach to learning about bioremediation.

\section{The Idaho Consensus Workshop}

We followed the Danish model for consensus workshops for the most part (changes will be noted below). A "Handbook for Conducting a Consensus Workshop," which describes in detail the workshop development and implementation is attached as Appendix A. In summary, we recruited a citizen panel of ten Southern Idaho citizens through advertisements in local newspapers (see Figure 1 for geographic distribution of panel members). A total of 28 individuals applied and we selected ten to become the citizen panel. There were five women and five men on the panel, ranging in age from 22 
to 70 years old. One panelist had a Ph.D., another a high school diploma, the others all had some college coursework or a college degree. One panelist had worked at the Idaho National Engineering and Environmental Laboratory (INEEL) in a non-technical position, while none of the others had any ties to the lab.

The panel met for three weekends at a central location; panelists all attended each session with the exception of one missed day for a family funeral (see schedule below in Figure 2). Each of the sessions was facilitated by a professional facilitator. The first two sessions were two days long (Friday and Saturday), with participants learning about bioremediation and other clean up activities at DOE sites from experts and through conversation among themselves. The last session was three days (Thursday through Saturday), with one day of meetings with experts and the remaining time devoted to preparing the consensus report. From the beginning, the workshop emphasized the goal of writing a consensus report that was based on the key questions the panel had about bioremediation.

One major difference between the workshop as discussed here and the Danish model is that, with the concurrence of the researchers, our panel chose not to have a conference to which the public was invited. As discussed further below, there were multiple reasons why the panel and the researchers chose not to have a public conference.

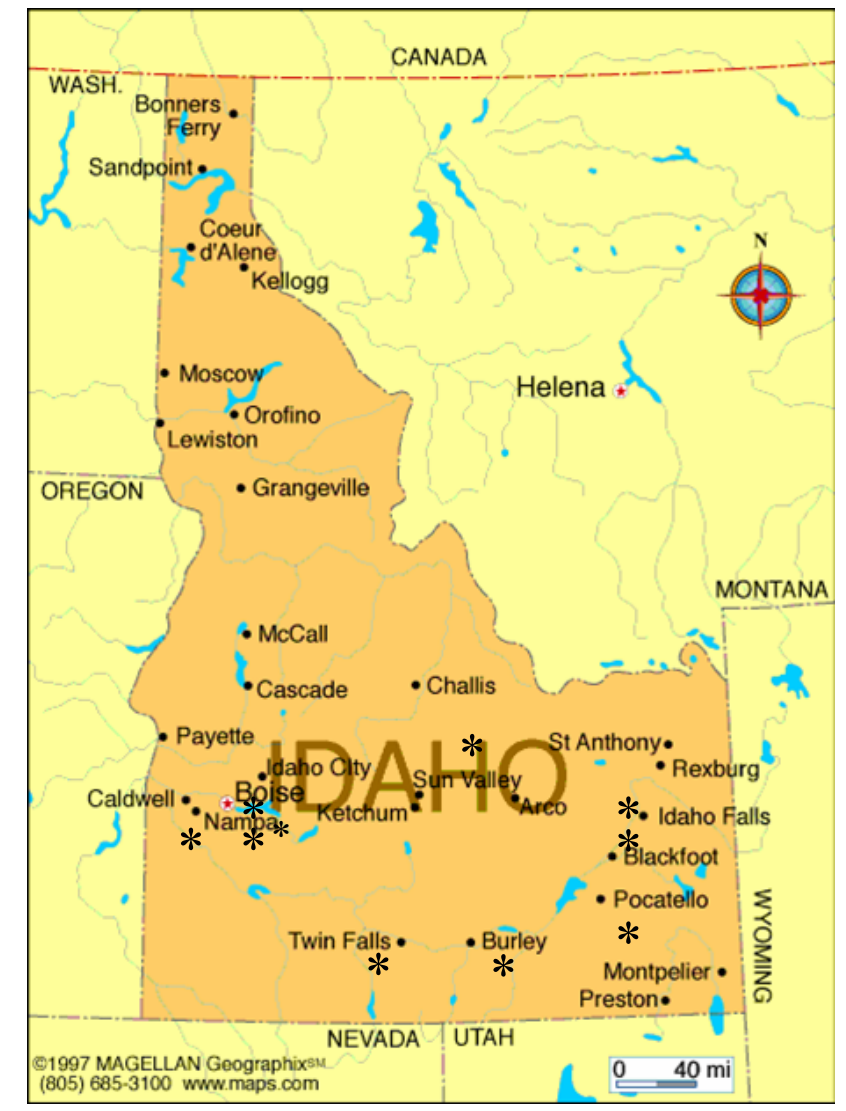

Figure 1: Geographic Distribution of Panel Members 
We asked all applicants to the workshop to complete a pre-test inventory asking for their attitudes and knowledge about bioremediation and DOE activities $(n=26)$. Respondents were asked to complete the same

Figure 2: Consensus Workshop

\begin{tabular}{|c|c|}
\hline Dates & Meeting Schedule \\
\hline Friday, July 19 & $\begin{array}{l}\text { Noon }-6 \text { pm; short } \\
\text { exercise after dinner }\end{array}$ \\
\hline Saturday, July 20 & $8: 30 \mathrm{am}-3 \mathrm{pm}$ \\
\hline Friday, August 9 & $\begin{array}{l}\text { Noon - } 6 \text { pm; short } \\
\text { exercise after dinner }\end{array}$ \\
\hline Saturday, August 10 & $8: 30 \mathrm{am}-3 \mathrm{pm}$ \\
\hline Thursday, September 12 & $\begin{array}{l}\text { Noon - } 6 \text { pm; short } \\
\text { exercise after dinner }\end{array}$ \\
\hline Friday, September 13 & $8: 30 \mathrm{am}-6 \mathrm{pm}$ \\
\hline Saturday, September 14 & $8: 30-3 \mathrm{pm}$ \\
\hline
\end{tabular}

survey approximately eight weeks after the completion of the workshop (22 weeks after the first survey, $n=20)$. We wanted to see if we would see any change in (1) the citizen panel responses and (2) differences between the citizen panel and others.

Table 1 describes responses to seven sample questions from the survey. While it's interesting to note that, on average, respondents find bioremediation

an acceptable technology (Question 3) and have great faith in technological solutions for the cleanup (Question 5), this is a small, non-random sample and therefore the results are not robust enough to generalize to a larger population. Table 1 does show that, prior to the Consensus Workshop, lay panel members and those who were not selected for the panel had very similar attitudes and perceptions.

Table 1: Pre-test Responses to Selected Questions

\begin{tabular}{|l|c|c|}
\hline & $\begin{array}{c}\text { Citizen panel } \\
\text { Mean }\end{array}$ & NonPanel Mean \\
\hline $\begin{array}{l}\text { 1. How concerned are you about the contamination at INEEL? } \\
\text { (1=not at all, 5= very) }\end{array}$ & 3.88 & 3.87 \\
\hline $\begin{array}{l}\text { 2. Is risk at INEEL currently increasing or decreasing? } \\
\text { (1=decreasing greatly, 5=increasing greatly) }\end{array}$ & 3.2 & 3.25 \\
\hline $\begin{array}{l}\text { 3. Given what you know, how acceptable is bioremediation as a } \\
\text { clean up technology at INEEL? (1=not acceptable, 5=very } \\
\text { acceptable) }\end{array}$ & 4.0 & 3.38 \\
\hline $\begin{array}{l}\text { 4. When it comes to cleanup at INEEL over the next 20 years or } \\
\text { more, how trustworthy is DOE? (1=very trustworthy, 5=very } \\
\text { untrustworthy) }\end{array}$ & 3.75 & \\
\hline $\begin{array}{l}\text { 5. I believe that science and technology will solve the long term } \\
\text { hazardous waste problems at INEEL. (1=agree,5=disagree) }\end{array}$ & 1.89 & 2.92 \\
\hline $\begin{array}{l}\text { 6. I believe that the federal government has the technical } \\
\text { competence to handle the long term hazardous waste problems at } \\
\text { INEEL. (1=agree, 5=disagree) }\end{array}$ & 2.56 & 3.08 \\
\hline $\begin{array}{l}\text { 7. I believe that the federal government is capable of responsible } \\
\text { financial management of public resources for long term } \\
\text { stewardship at INEEL. (1=agree, 5=disagree) }\end{array}$ & 2.78 & \\
\hline
\end{tabular}


As shown in Table 2 below, perceptions of both panelists and non-panelists made only small shifts during the period between the pre-and post-tests (this may be an artifact of the small number of respondents). Once again, due to the small sample size, we cannot generalize from these responses to any larger population but it is interesting to note some of the larger shifts in attitudes. Comparing pre- and post-test means on Question 3, the acceptability of bioremediation for the panelists went up slightly, while it went down for the non-panelists. Belief that science and technology will solve the long term hazardous waste problems at INEEL (Question 4) shifted slightly in a positive direction for panelists while it changed more significantly for non-panelists in a negative direction. On the other hand, panelists registered some increased concern about contamination at INEEL, while non-panelists were slightly less concerned (Question 1). Also, non-panelists expressed greater belief that the federal government is capable of responsible financial management, while panelists showed a very small shift toward a negative view in this area (Question 7).

Table 2: Post-test Responses to Selected Questions

\begin{tabular}{|l|c|c|}
\hline & $\begin{array}{c}\text { Citizen panel } \\
\text { Mean }\end{array}$ & NonPanel Mean \\
\hline $\begin{array}{l}\text { 1. How concerned are you about the contamination at INEEL? } \\
\text { (1=not at all, 5= very) }\end{array}$ & 4.22 & 3.6 \\
\hline $\begin{array}{l}\text { 2. Is risk at INEEL currently increasing or decreasing? } \\
\text { (1=decreasing greatly, 5=increasing greatly) }\end{array}$ & 3.11 & 3.13 \\
\hline $\begin{array}{l}\text { 3. Given what you know, how acceptable is bioremediation as a } \\
\text { clean up technology at INEEL? (1=not acceptable, 5=very } \\
\text { acceptable) }\end{array}$ & 4.11 & 3.89 \\
\hline $\begin{array}{l}\text { 4. When it comes to cleanup at INEEL over the next 20 years or } \\
\text { more, how trustworthy is DOE? (1=very trustworthy, 5=very } \\
\text { untrustworthy) }\end{array}$ & 2.33 \\
\hline $\begin{array}{l}\text { 5. I believe that science and technology will solve the long term } \\
\text { hazardous waste problems at INEEL. (1=agree,5=disagree) }\end{array}$ & 2.89 & 2.25 \\
\hline $\begin{array}{l}\text { 6. I believe that the federal government has the technical } \\
\text { competence to handle the long term hazardous waste problems at } \\
\text { INEEL. (1=agree, 5=disagree) }\end{array}$ & 2.89 & 2.70 \\
\hline $\begin{array}{l}\text { 7. I believe that the federal government is capable of responsible } \\
\text { financial management of public resources for long term } \\
\text { stewardship at INEEL. (1=agree, 5=disagree) }\end{array}$ & & \\
\hline
\end{tabular}

All of the respondents (both panelists and non-panelists) provided written comments on their post-tests, but their concerns were distinctly different. The panelists were most likely to comment on how participating in the consensus workshop raised their knowledge about bioremediation and other cleanup activities at DOE sites as well as highlighted the need for meaningful public involvement such as the consensus workshop. For example, one participant said "more education allowed me greater understanding and therefore I feel I am more capable of making a more rational decision...” Another told us that "my views have changed in that I now realize that public involvement is a must in 
order to make change happen.” On the other hand, non-participants most commonly expressed concerns similar to this one: "I still worry how such a huge project can be done consistently and safely at a time when the government is cutting back on the budget.” Another was more explicit, “...because the Republican agenda does not contain satisfactory plans for environmental protection ... the INEEL will be a safety concern for all of us for several decades in the future.”

\section{Lessons Learned: Participants Concerns about Bioremediation}

Participants' concerns and conclusions are summarized below and described in more detail (and in their own words) in the consensus report (Appendix F). Six major concerns emerged among participants including:

- Bioremediation technology

- Health and risk assessment

- Comparing bioremediation technology to other cleanup technology

- Education and Outreach

- Liability and Responsibility

- Longterm Stewardship

\section{A. Bioremediation Technology}

Participants were able to sort through the difficult reading material and listen to extended presentations by scientists with assistance from the resident expert (member of the Advisory Board) and the facilitator. Because of their preparation and coaching from the resident expert, participants were quite familiar with technical terms and technology issues by the end of the workshop. In general, participants characterized bioremediation as an "effective way of treating contaminants to lessen their negative effects." They also noted that bioremediation can lower costs of cleanup and reduce exposure to toxic material. Their concerns included:

- Limited testing of bioremediation to clean up radionuclides and heavy metals.

- Whether or not bioremediation is effective in the vadose zone and at deep levels.

- Using bioremediation for sites that have multiple contaminants.

- Some concern (but not great) about potential mutation of bacteria in presence of radioactive waste.

- The effects of long-term clogging of aquifers.

- Complicated geology and other site characteristics that make it difficult to translate results of bioremediation tests from site to site.

All of these concerns and issues were discussed in great detail with specialists and appear to accurately reflect the current state of bioremediation science. 


\section{B. Health and Risk Assessment}

Participants' major concerns were related to the health risks associated with contamination at the site and methods for avoiding exposure, favoring technologies that lower risk to residents and workers. They characterize bioremediation as a "good" technology because contaminants are most likely to remain in the ground, reducing exposure pathways. They did express some concern that bioremediation may concentrate contaminants thereby creating a potentially larger risk than prior to bioremediation. While participants agreed that risk assessments should accompany technology implementation, they were concerned that the assessment could not anticipate future changes in the conditions.

Concerns about health and safety permeated most panel discussions and appear to drive many, if not most, of their concerns about the technology (although this concern extended to all technologies, see next section). When participants heard that bioremediation has the potential to reduce exposure and appears to present no new risks to the public or workers, it became more acceptable to them. When presentations or conversations suggested otherwise, they raised additional questions and objections.

\section{Comparing Bioremediation to Other Technologies}

Participants were extremely interested in comparing the costs and effectiveness of bioremediation to other cleanup technologies. Their concerns were based on the idea that if a technology is too expensive or takes too long to complete the job, cleanup may not be completed. Again, one of the major comparisons for the participants was the amount of potential exposure posed by various technologies. In general, they considered the immobilization of radionuclides and heavy metals through bioremediation an effective method primarily due to the cost of alternatives and the increased risk of exposure with other technologies.

\section{Education and Outreach}

Through participation in the consensus workshop, panelists gained significant confidence in their ability to understand technical issues and contribute to any ongoing discussion about cleanup activities at the INEEL. They characterized information they currently receive from the lab as "public relations," presenting a "spin" rather than unbiased information. They also believe that information is presented at either a simple, patronizing level or is so highly technical as to be incomprehensible. Participants suggest that on-going education and information dissemination through multiple media (e.g., meetings, web sites, newspaper and radio stories, etc.) is critical so that citizens with different learning styles and/or access to information have access to the information. They are most likely to trust information that comes from sources external to DOE/INEEL. 


\section{E. Responsibility and Liability}

During early stages of the discussion, participants wanted to know who was at fault, who could be held responsible for cleanup failures at the INEEL site. After several presentations and ongoing conversations among themselves, they began to realize the complexity of the contamination, site geomorphology, and political and regulatory requirements makes "blame" hard to place. In fact, they came to the conclusion that the public is also responsible for the cleanup including learning about what's going on at the site, electing officials who make the cleanup a priority, and getting involved in public decision making opportunities.

Due to the long-term nature of bioremediation strategies, participants were concerned about continued oversight of and financial commitment to cleanup efforts. They were interested in seeing some sort of insurance, bonding, or other financial mechanism be available to off-set any unexpected costs of implementing bioremediation strategies or unforeseen health effects resulting from the technology.

\section{F. Long-term Stewardship}

Due to the long period of radioactivity for some contaminants at DOE sites, participants were quite concerned about a continuing (and continuous) commitment to cleanup activities. Panelists perceive bioremediation of radionuclides and heavy metals as requiring a multi-millennia commitment for funds, technology, and oversight, and were not totally convinced that current arrangements will supply these resources. Their specific concerns included:

- Ever-changing political climate

- Multiplicity of agencies and laws involved in cleanup decisions at publicly owned sites

- Agency and oversight committee changes and turnover

- Legal and regulatory changes

- Difficulty in instituting long term stewardship

- Determining what length of time we mean by "long term"

- Ability to meet the communities' vision of restoring the land for human use

While participants generally found bioremediation of contaminants at DOE sites an acceptable strategy, they do have remaining questions and concerns. Their technical concerns reflect the emerging nature of bioremediation research, especially for radionuclides and heavy metals, calling for continued research. Most of their concerns can be characterized as non-technical aspects of technology development. As shown below in Table 3, respondents to the pre- and post-tests were generally comfortable with the technical competence of DOE and its general commitment to long term restoration of the site (questions a and g), although non-panelists had a negative shift in attitude about DOE's commitment to long term cleanup. Panelists had a significant increase in their belief that DOE is technically competent and a good manager of public funds after their participation in the workshop. Respondents were less sanguine, however, in their 
characterization of DOE processes for specifically involving and informing the public about their activities (question d).

Table 3: Perceptions of DOE Commitment to Site Cleanup

Range: Definitely No $=1$ to Definitely Yes $=5$

\begin{tabular}{|c|c|c|c|c|}
\hline \multirow{2}{*}{$\begin{array}{l}\text { When it comes to cleanup at INEEL over the } \\
\text { next } 20 \text { years or more, do you feel that the DOE } \\
\text { is.... }\end{array}$} & \multicolumn{2}{|c|}{ Panel Mean } & \multicolumn{2}{|c|}{ Non-Panel Mean } \\
\hline & Pre-test & Post-test & Pre-test & Post-test \\
\hline a. Technically competent? & 3.38 & 4.00 & 3.36 & 3.33 \\
\hline b. A good manager of public funds? & 2.14 & 2.78 & 2.67 & 2.56 \\
\hline $\begin{array}{l}\text { c. Open and honest about its cleanup } \\
\text { activities? }\end{array}$ & 2.50 & 2.44 & 2.43 & 2.67 \\
\hline $\begin{array}{l}\text { d. Good at providing information about its } \\
\text { cleanup activities? }\end{array}$ & 2.38 & 2.44 & 2.70 & 2.30 \\
\hline $\begin{array}{l}\text { e. Concerned and caring about the public's } \\
\text { health? }\end{array}$ & 3.11 & 3.11 & 3.0 & 2.70 \\
\hline $\begin{array}{l}\text { f. Concerned and caring about the } \\
\text { environment? }\end{array}$ & 3.0 & 2.78 & 2.69 & 2.60 \\
\hline $\begin{array}{l}\text { g. Committed to long term cleanup of the } \\
\text { INEEL site? }\end{array}$ & 3.14 & 3.38 & 3.0 & 2.50 \\
\hline
\end{tabular}

Participants in the consensus workshop were able to engage in meaningful conversations with specialists and among themselves about the highly complex cleanup needs and emerging technologies at DOE sites with some assistance in translating technical documents and presentations, review of details from multiple disciplines and perspectives, and enough time to concentrate on the topic. Specialized materials and presentations from experts helped in this learning and are discussed in more detail below.

\section{Lessons Learned: Materials and Delivery Methods to Address Bioremediation}

\section{A. Identifying Potential Issues and Preparing Introductory Materials}

We held an initial planning session with members of our Advisory Committee (see Figure 4) to review the workshop process and to generate topics they thought might be raised by the citizen panel. Advisory Committee members were selected for their knowledge about bioremediation and/or the INEEL site. See Appendix C for the list of almost 50 issues they thought the panel might be interested in. Potential questions include concerns about the types of contamination, the technology itself, the risks and limitations 
of bioremediation, alternatives to bioremediation, and socio-political concerns. We also asked the Advisory Committee for assistance in developing a list of experts who might be appropriate speakers at a workshop meeting. The Advisory Committee was able to generate both topics and potential speakers that were very close to the types of issues ultimately raised by the panel during the workshop. Working with the Advisory Committee prior to the workshop gave us a head start on planning for the sessions although their perceptions of what the panel might be interested in were never substituted for panel input.

Figure 4: Advisory Board Members

\begin{tabular}{|ll|}
\hline \multicolumn{1}{|c|}{ Name } & \multicolumn{1}{c|}{ Affiliation } \\
\hline $\begin{array}{l}\text { Dr. Kenneth } \\
\text { Williamson }\end{array}$ & $\begin{array}{l}\text { Chair, Civil, Construction, and Environmental Engineering, Oregon } \\
\text { State University }\end{array}$ \\
$\begin{array}{l}\text { Dr. Lewis } \\
\text { Semprini }\end{array}$ & $\begin{array}{l}\text { Professor, Civil, Construction, and Environmental Engineering, } \\
\text { Oregon State University }\end{array}$ \\
Janice Brown & $\begin{array}{l}\text { Advisory Scientist, Ecological and Cultural Resources, Idaho } \\
\text { National Engineering and Environmental Laboratory }\end{array}$ \\
& Senior Technologist, CH2MHill \\
\hline
\end{tabular}

We also worked with members of the Advisory Committee to prepare the Bioremediation Introductory paper for the panel members. Using information from the Department of Energy (McCullough et al.) and other sources, we developed an "Introduction to Bioremedation at U.S. Department of Energy Sites” (attached as Appendix B). Each time this introductory paper was revised for readability, we had one or more members of the Advisory Committee review the changes to make sure the information was still scientifically correct. While simplified from existing DOE materials, the introductory paper is still written at about the $12^{\text {th }}$ grade level due to the number of scientific terms used in the paper. The paper was delivered to panel members three weeks before the first workshop for review. All panel members reported that they read the introductory paper prior to the workshop and remarked that they liked getting this and other handouts so they could read and prepare on their own schedule. Creating appropriate materials for the workshop required assistance from science writers and scientists to ensure that scientific accuracy is not sacrificed to readability.

\section{B. Using a Facilitator}

A facilitator was necessary for an effective workshop due to the complexity of the topic, the seven day workshop format, and Principal Investigators' interest in observing the process. We were interested in a facilitator with some scientific background who would not be overwhelmed by the technical details of the topic, but who would not be so knowledgeable as to dominate the panel discussions. An effective facilitator must be 
able to address the complexities of the technical details while managing the complicated workshop design to ensure that all panel members are effective participants.

All of the workshop sessions were led by the professional facilitator who helped design the meetings, conduct the workshops, and debrief each session. At the end of each session when asked to identify what worked and what didn't, panel members always described the facilitator as skilled at keeping the workshop on track, getting people to express their questions and concerns, and helping them understand the tough topics they were learning about. Moreover, the facilitator we used brought high energy and good humor to a demanding process for the panel members. She kept tasks tightly focused and timed, made sure that panel members were successful in completing tasks, and reminded them how each activity contributed to the overall goal of writing the consensus report. In addition, the facilitator acted as a translator with some of the scientists or specialists who were less clear in their presentations and/or answers to questions. A strong facilitator who can engage panel members in hard work and co-learning is critical to the success of a consensus workshop.

\section{Working with Scientists and Managers}

The format of the consensus workshop offers panel members multiple opportunities to interact with and question "experts" on topics of the panels' choice. On the first day of the workshop, the group discussed the types of scientists and managers they were interested in learning with. In general they were looking for people with the minimum qualifications of:

- Excellence in field

- Good communicator

- Broad points of view

- Wide perspectives

Criteria developed by the panel helps to ensure that scientists and managers selected to participate in the workshop address panelists' perceived and actual needs.

During the first session, one member of the Advisory Committee presented an "Introduction to Bioremediation" to the panel, reviewing material in the Introductory Paper and answering panelists' questions. This session took several hours, as participants struggled to understand the details of bioremediation. The format of this session was not like a typical workshop presentation or even like a traditional lecture; instead it was very interactive and iterative, with participants engaged in dialogue with the presenters and among themselves as they learned more about bioremediation. It takes several hours of presentation by a patient expert with excellent communication skills and dialogue with panelists to adequately introduce a complicated technical subject topic.

The facilitator used her scientific background to translate specialists' presentations to the panel members as well as panelists' questions for the specialists. In addition, a technical 
steering committee member attended all workshop sessions and was available to answer panel members' questions, assist in framing questions, and help translate presentations. Finally, a representative from the INEEL attended many of the workshop sessions and provided background detail about past and current activities at the site. It was helpful to have technical specialists available throughout the workshop sessions to provide answers to emerging questions and to act as a liaison between specialists and panelists as appropriate.

Most of the specialists who participated in the workshop had a difficult time making the transition to using language and concepts that the citizen panel understood. When inviting a speaker, we explained the purpose of the workshop, described the types of people on the panel, and provided a list of questions that the panel was interested in discussing. We also talked with the speakers about the appropriate level of language and advised them that panel members were learning through questions and dialogue (rather than passive listening). Even with instructions to the contrary, speakers tended to present a lot of specific detail about their subject prior to engaging the panel. The panelists who had little or no background in the discipline of the speaker found themselves lost after the first unfamiliar acronym, chemical name, or complicated graph. The facilitator and/or resident expert often stepped in to ensure that panelists understood the technical details. Preparing specialists for their presentation is aided by providing specific examples and recommendations for appropriate language, graphics, and presentation styles.

During the debrief, panel members expressed concern that the invited specialists did not directly answer their questions and made presentations that were only sometimes on target. Panel members felt that they heard the most honest responses from scientists and managers during the specialist panel at the end of each day when they interacted together spontaneously. Specialists directly engaged panel members' questions and concerns through their conversations among themselves as well as in response to panelists. Providing time for specialists to talk with each other and the panel members ensures that citizen panel members understand what the specialists present as well as provides another opportunity to get questions answered.

\section{Additional Materials and Delivery Methods}

We asked specialists to provide only limited materials to the panelists until they requested more specific information. All presentations, other electronic materials, and links to relevant sites were posted on a project web site (http://cwest.orst.edu/nabir/index.htm) that participants could access if interested. All participants except one had relatively easy access to the internet. Information developed during this project is available to the public, including the final consensus report. The limited cost of developing the web site and keeping it up to date was well spent for those participants drawn to this additional material even though some never went to the web page. 


\section{Lessons Learned: Effectiveness of the Consensus Workshop for Involving the Public in a Dialogue about Bioremediation}

We use the following questions drawn from the literature reported above to assess the effectiveness of the consensus workshop:

- Did the workshop identify the variety and complexity of citizen attitudes about bioremediation?

- Were the participants independent from institutions and/or individuals promoting specific technologies and/or approaches?

- Was the workshop process transparent to both participants and observers?

- Was there clear task definition that is reflected in finished products?

- Was the workshop cost effective?

\section{A. Identification of Citizen Attitudes about Bioremediation}

We were able to elicit detailed and sophisticated characterizations of a full range of citizen attitudes and concerns about bioremediation through the workshop process. Within the panel there was a wide diversity of life experience and education, but virtually no knowledge about bioremediation prior to the workshop. As described above in Section 3 and in the Consensus Report (Appendix B), panel members were able to articulate a wide range of issues and concerns regarding bioremediation in particular, and the DOE cleanup strategy in general. Panel members became quite comfortable with the technology of bioremediation through the workshop materials, presentations, and discussions and asked increasingly sophisticated questions of specialists. The questions they raised about using bioremediation to clean up radionuclide and heavy metal contamination reflect the emerging research agenda, and focused on use of bioremediation at geographically complex sites and limited testing of bioremediation in vadose zones and deeper levels.

Most of the panel's concerns were directed to implementation of bioremediation including questions of exposure and health risk, cost effectiveness (compared to other clean up technologies), and responsibility for oversight of bioremediation (and other cleanup activities) over the long term. While these are not surprising concerns, panelists' reservations were tempered by their knowledge and general acceptance of bioremediation technology and focused on specific issues (e.g., worker exposure during different stages of bioremediation) rather than generalized fears or ideological positions. 


\section{B. Independent Participants}

\section{Paid Learning Opportunity!}

Would you like to participate in research, conducted by Oregon State University, that looks at how to involve the public in decisions about cleanup technology?

This is an opportunity to learn about an actual hazardous substance cleanup technology, as well as participate in research to find better ways to involve the public in decisions about cleanup. Those selected to participate will learn about the technology of bioremediation in three weekend sessions, held in southern Idaho, on these dates:

July 19-20, 2002 (Friday and Saturday) August 9-10, 2002 (Friday and Saturday) September 12-14, 2002 (Thursday, Friday, and Saturday)

If you wish to apply, you must be available to attend on all of these dates and be aged 18 or older. You must have no expert knowledge of or previous connection with bioremediation. Costs of car travel, lodging, and meals will be paid and each participant will receive a significant monetary stipend in one payment at the conclusion of the three sessions.

Are you interested? Write a brief letter (one page) describing yourself and why you would like to participate. Include your name, address, and telephone number. Mail to:

Stephanie Sanford, Project Manager

210 Strand Agriculture Hall

Oregon State University

Corvallis, Oregon 9733 i

Telephone: 1-800-653-6110 or 541-737-5861
We placed ads in four local newspapers (Boise, Idaho Falls, Pocatello, and Twin Falls) asking for workshop participants. We wanted to select a "representative" panel so that the widest array of viewpoints and experiences possible would be brought to the discussions of a relatively small group of people. Criteria for selection included no "expert knowledge or previous connection with bioremediation." Applicants were asked to tell us why they were interested in participating and a little bit about themselves. We received a total of 28 applications and would have preferred to have about 50 from which to select. We used the

information provided by the applicants to select a panel that represented the widest possible diversity as to gender, age, education, income, and religion.

During the debriefing we heard from panelists that they thought the request for research participants was a "hoax," like stuffing envelopes at home. We talked with or communicated in some way with all participants before they applied. Many had questions about what would be expected of them, how difficult it was going to be, and concerns about our legitimacy. We were told by participants that this individual attention reduced their fears. Panelists also told us that because we were from an out-of-state university they didn't feel we would be as biased as someone from Idaho. Initial and continuing contact with panelists was critical in the weeks prior to the first meeting to reduce their anxiety as well as to begin creating dynamics of respect among participants, planners, and facilitator.

When asked why they applied, the most common responses involved participants' interest in learning in general, getting paid to learn, concern about the site, and desire to get involved in community based efforts. While participants had a wide variety of ideological and political perspectives, none came to the workshop to convince others of that perspective and none represented a larger group agenda. One of the respondents remarked at the end of the workshop, "This was a huge learning experience," which other panelists echoed. Given the opportunity, individual members of the public are open to learning about difficult technical issues that have an impact on their lives. 
Making sure that the panelists heard from a wide number of perspectives was as critical as having multiple viewpoints among the participants. As seen in Appendix $\mathrm{E}$, the panel worked with an elected official, NABIR scientists doing research at the cutting edge of bioremediation, consultants implementing bioremediation tests in the field, federal and state agency scientists working on issues related to geology and risk assessment, and lawyers. The panel members themselves identified the types of specialists they wanted to hear from and the project staff worked to find people from a diversity of organizations and institutions who could work with the group.

\section{Transparent Processes}

The Danish-style consensus conference includes at least one session open to the public during which panelists and specialists are observed and questioned by others; the NIHstyle consensus conference does not include this feature. We asked panelists if they would like to hold an open session and they declined for several reasons. Primarily they felt that the informal give and take with the specialists, which they felt was most conducive to learning about the issues, would be compromised in a more formal setting. They were afraid that they would "ask stupid questions in front of their friends or community members" and refrain from engaging the specialists. During the debriefing panelists decided this early fear was unfounded as they watched everyone from panel members to project staff to the specialists themselves ask "stupid questions" about a complicated subject. In addition, the site selected for the workshop sessions was a small town midway across the state, with few facilities for holding a public meeting. We would have needed to move to a larger town to hold the meeting, necessitating increased travel time for many participants. Inviting the public to at least one question and answer session with specialists may provide wider access to information provided for the panel and ensure that all perspectives are addressed by the panel.

While most panelists expressed no regrets that a public session was not scheduled they were concerned about how widely their concerns would be dispersed. They wondered how they could continue to learn about bioremediation and other issues at the INEEL and how they could communicate what they'd learned to their neighbors and friends. Although most panelists clearly understood the research nature of the project, they hoped that their report and concerns about bioremediation would be of use to the DOE and INEEL.

\section{Clear Task Definition Reflected in the End Product}

The ultimate outcome of the workshop is a consensus report detailing what the panel members learned about the technology, and characterizing their concerns and remaining questions (see Appendix F). The report is written by all panel members together with no direction (but plenty of assistance) from the facilitator and the project staff and signed by all panelists at the end of the workshop. The panelists began by developing an outline of what they wanted to include in the report. They broke into small groups of about three people with each group preparing a draft of one section. Each small group brought its draft sections back to the larger group for review and revisions. The revised sections 
were reviewed by the whole group a final time when the entire draft was complete. An iterative writing and review process ensured that the contents of the report reflected the consensus view of the entire panel but was only possible because they had developed trust among themselves that each small group was going to represent the views of the panel.

We provided an example of a report written by another consensus conference panel as a resource, but the panel created a report that reflected their own concerns and styles. They told us several times that they wanted the report to be "in their own words," although there was some debate about whether the DOE would be able to "hear" their concerns if they weren't couched in technical language. During the debriefing, panelists told us they were surprised at how little the project staff was involved in writing the final report. One panelist remarked, "I did wonder how much ownership we would have; I was worried the staff would try to read our minds. You didn't do th[at] at all.” Ultimately, the success of the workshop is reflected in the ability of the panelists to write a consensus report that reflects its concerns in their own voice.

\section{E. Cost Effective}

Traditionally, citizens have not been paid for their involvement on Federal advisory boards even though agency staff and professional members participate and are paid as part of their professional duties. We rely on citizens becoming involved for months and even years on committees and boards, giving up time they could spend with their families, their jobs, and their leisure pursuits. Or, we ask members of the public to come to a public hearing (scheduled for one long evening during the work week) and provide comments on a report or proposal about which they have little, if any, information. An investment of both time and money is required to educate people about technical issues and to implement strategies to elicit serious input.

One of the innovative aspects of this workshop was a $\$ 2500$ stipend paid to the panel members for their participation. We asked panelists to take several hours to prepare for each workshop session, spend seven days (and five nights) away from their families and jobs, and work hard to learn about a technical subject. As one panelist said, "We worked really hard for this [stipend]. Sometimes it was hard to get going, but the stipend was enough to keep me going." None of the panelists knew what the stipend would be before they applied and when asked, all reported that they thought it would be in the $\$ 250-500$ range. Another told us "I never once thought about how much it would be until you told me. ... I thought it was so great to be asked to provide an opinion or participate and to get paid, that's great." Some participants used the stipend to off-set lost salary and/or to pay for day care. One told us that he "had to keep reiterating the amount to [his] wife," she wouldn't let him do it for free because he left two small children at home for three summer weekends. While many of the participants would not have been able to participate for the entire workshop without some kind of stipend, most would have participated for less $(\sim \mathbf{1 0 0 0})$ because they were interested in the project and/or the topic, not the money. 
Another innovative aspect of the workshop is bringing the participants together in multiday working sessions away from their daily lives. Having participants live and work together at a single site allowed them to work long hours as necessary and also contributed to a sense of camaraderie among participants. Due to the low costs of the area in which we held the workshop, we were able to budget less than $\$ 120$ for hotel, meals, and mileage reimbursement for each participant per trip (total budget about \$3500). When looking for a workshop site, we took into consideration the cost of lodging and meals. Providing on-site services and expense reimbursement to participants creates a professional atmosphere that promotes a sense of purpose and seriousness about tasks.

One additional aspect of cost effectiveness of public involvement activities is the amount of time invested in the effort. The consensus workshop is relatively short term - three months for the workshop itself with an additional three to six months preparation - and is finite. When the consensus report is signed, the process is complete. A final product describing the process, the questions, and the recommendations of the group is available to all who are interested in the results. A project web page may exist for an extended period of time but does not need to be maintained after the final report is posted. Unlike other public involvement activities, it is possible to accurately budget for costs of a consensus workshop and have a final product in hand at a date certain.

\section{Conclusions}

While educating people ten to twenty individuals at a time may seem daunting, panelists' gained high levels of knowledge about bioremediation and about group process in a relatively short time. As described in the Consensus Report and in our debriefing sessions, participants in the consensus workshop believed that "it worked" as a way to engage them in "learning about bioremediation in a factual way." They believe that the quality of information they received and interactions they had with other citizens and with specialists were due to the workshop design and processes. They recognize that impartial participation is crucial, but also enjoyed working with specialists who are passionate about what they do; it offered them insights into jobs and organizations they previously had no access to. Citizens who came to the workshop worried that they could never learn about this complicated technology are now willing to talk to friends, neighbors, and other citizen groups about bioremediation (from final report).

\section{7. $\quad$ References Cited}

Davison, A., I. Barns, and R.Schibeci. 1997. Problematic Publics: A Critical Review of Surveys of Public Attitudes to Biotechnology. Science, Technology \& Human Values 22 (3): 317-348.

Jorgensen, T. 1995. Consensus Conferences in the Health Care Sector. In S. Joss and J. Durant, editors, Public Participation in Science: the Role of Consensus Conferences in Europe. London: Science Museum. 17-29. 
Joss, S. and J. Durant, editors. 1995. Public Participation in Science: the Role of Consensus Conferences in Europe. London: Science Museum.

Kluver, L. 1995. Consensus Conferences at the Danish Board of Technology. In S. Joss and J. Durant, editors, Public Participation in Science: the Role of Consensus Conferences in Europe. London: Science Museum. 41-49.

McCullogh, J., T Hazen, S. Benson, F.B. Metting, and A. Palmisano. Bioremediation of Metals and Radionuclides ... What it is and how it works. A NABIR Primer. Office of Biological and Environmental Research, Office of Science, U.S. Department of Energy.

Rowe, G. and L.J. Frewer. 2000. Public Participation Methods: A Framework for Evaluation. Science, Technology \& Human Values 25 (1): 3-27. 


\section{Appendix A: A Manual for Conducting Consensus Workshops}

\section{CONSENSUS WORKSHOP MANUAL}

\section{INTRODUCTION}

The consensus workshop described in this manual is a strategy for public participation that focuses on education as a means of involving stakeholders in technology assessment and policy-making. Based on research conducted by Oregon State University faculty and funded by the U.S. Department of Energy's Natural and Accelerated Bioremediation Research (NABIR) program, this manual describes a community involvement approach that gives the public significant say in how an issue is defined and what resources are utilized in the decision-making process. These characteristics make it an excellent method of citizen involvement for controversial issues that are technically complex.

This manual is written for those interested in organizing a consensus workshop themselves, providing detailed information about the planning, implementation, and evaluation of a workshop. The manual is divided into 8 main sections: Introduction, What is a Consensus Workshop, Overview of the Workshop Schedule, Timeline for the Process, Key Players, Major Processes, Special Considerations, and Summary. Included in the description of the major processes of a consensus workshop are ideas for "strategies," "equipment," and "outcomes." Highlighted items are major tools or documents used in the workshop for which samples are included in the Appendices.

\section{WHAT IS A CONSENSUS WORKSHOP?}

The consensus workshop described in this manual was developed through research that sought new ways of involving the public in decisions about use of technology. The consensus workshop is derived from both the "consensus development conference" first used by the National Institutes of Health $(\mathrm{NIH})$ in the United States and the "consensus conference" approach to technology assessment used most recently in Europe and Australia. Like these two original models, the consensus workshop is grounded in the idea that to be accepted and sustained, technology assessment and policy must be socially negotiated rather than narrowly defined by a group of "experts." It establishes a dialogue between the public and the professional community with the goal of making technology understandable, while validating questions and perspectives held by the public. The strengths of this model for community involvement are a high degree of participant independence, early public involvement, high transparency of the process to the public, public resource accessibility, clear task definition, and cost-effectiveness. One significant difference between the consensus workshop as described here and the earlier models mentioned above is the fact that the "consensus conference" includes a conference event, where citizen panel members select presenters for a larger public audience. A conference event may be added to the consensus workshop design presented here.

A consensus workshop involves a small group of interested citizens (10-14 non-experts), selected to represent a variety of backgrounds and attitudes characteristic of their community. This "citizen panel" meets for two 2-day sessions and one 3-day session to learn about the technology or issue 
of concern and to write a consensus report based on what they have learned. Once provided with introductory material, the citizen panel members determine what they would like to learn and from what sources information should be drawn. Citizen panel members and experts discuss the major issues identified during the workshop meetings. Throughout the workshop the citizen panel moves toward consensus on the issue of concern; their conclusions and recommendations are documented in the written consensus report. The consensus workshop is organized by one or more project managers and guided by a professional facilitator.

\section{OVERVIEW OF THE WORKSHOP SCHEDULE}

Key considerations in scheduling the consensus workshop include: 1) balancing the two major tasks for the citizen panel of learning about the issue of concern and writing a consensus report about it; 2) finding a location for the workshop that is as convenient as possible for travel by the citizen panel and others; and 3) utilizing citizen panel travel and meeting time efficiently. The overview below shows a schedule that provided morning travel time before each meeting and afternoon travel time after each meeting.

\begin{tabular}{|c|c|}
\hline MEETING/DAY & MAJOR ACTIVITIES \\
\hline Meeting 1 & $\begin{array}{l}\text { Develop commitment among citizen panel members; introduce members to the } \\
\text { workshop process and the issue; develop questions, the answers to which will form the } \\
\text { content of the consensus report. }\end{array}$ \\
\hline $\begin{array}{l}\text { Day } 1 \\
\text { Noon-8:30 p.m. }\end{array}$ & $\begin{array}{l}\text { Introductions; overview of the workshop process; group mission, charter, expectations } \\
\text { for how panel members treat each other; basics of the issue of concern; questions and } \\
\text { discussion. }\end{array}$ \\
\hline $\begin{array}{l}\text { Day } 2 \\
\text { 8:00 a.m.-3:00 } \\
\text { p.m. }\end{array}$ & $\begin{array}{l}\text { Review of Day 1; formulation of the questions about the issue; identifying desired } \\
\text { expertise to address the questions; review, feedback, next steps. }\end{array}$ \\
\hline Meeting 2 & $\begin{array}{l}\text { Learn about the issue of concern; draft outline of consensus report; decide how to write } \\
\text { the report. }\end{array}$ \\
\hline $\begin{array}{l}\text { Day } 3 \\
11: 00 \text { a.m. }-7: 00 \\
\text { p.m. }\end{array}$ & $\begin{array}{l}\text { Revisit mission and charter; hear from professional managers and scientists; identify } \\
\text { remaining questions; dialogue with panel of presenters. }\end{array}$ \\
\hline $\begin{array}{l}\text { Day } 4 \\
\text { 8:00 a.m.-3:00 } \\
\text { p.m. }\end{array}$ & $\begin{array}{l}\text { Review information from Day 3; revise and finalize questions; develop consensus report } \\
\text { outline; decide on process for writing report; practice drafting section of report. }\end{array}$ \\
\hline Meeting 3 & $\begin{array}{l}\text { Learn further about issue of concern; write and complete final draft of consensus report; } \\
\text { celebrate. }\end{array}$ \\
\hline $\begin{array}{l}\text { Day } 5 \\
11: 00 \text { a.m. }-8: 00 \\
\text { p.m. }\end{array}$ & $\begin{array}{l}\text { Hear from professional managers and scientists; identify remaining questions; dialogue } \\
\text { with panel of presenters; review report outline and draft sections of report. }\end{array}$ \\
\hline $\begin{array}{l}\text { Day } 6 \\
\text { 8:00 a.m.-8:30 } \\
\text { p.m. }\end{array}$ & $\begin{array}{l}\text { Review information from Day 5; discuss sample consensus report; draft entire report; } \\
\text { review entire draft. }\end{array}$ \\
\hline $\begin{array}{l}\text { Day } 7 \\
\text { 8:00 a.m.-3:00 } \\
\text { p.m. }\end{array}$ & $\begin{array}{l}\text { Write cover letter/executive summary of report; document consensus on each section } \\
\text { of the report; debrief the workshop process; celebrate. }\end{array}$ \\
\hline
\end{tabular}




\section{TIMELINE FOR THE PROCESS}

The timeline for the consensus workshop will vary based on factors such as the immediacy of holding the workshop, the extent to which the workshop is the sole focus of work for the project managers, and the availability of the citizen panel members to meet. The timeline below was used in a situation in which the citizen panel meetings were 3-4 weeks apart (Months 6, 7 and 8) for a project that accounted for less than half-time work for all three project managers. The timeline shows the key activities for each month of the workshop and refers to the relevant major processes described in that section of the manual below.

\begin{tabular}{|l|l|c|}
\hline MONTH & ACTIVITY & MAJOR PROCESS \\
\hline Month 1 & Appoint Advisory Committee; hold Advisory Committee meeting. & A \\
\hline & $\begin{array}{l}\text { Establish dates for workshop; begin search for venue; develop } \\
\text { citizen panel recruitment and selection strategy. }\end{array}$ & B, C \\
\hline Month 2 & $\begin{array}{l}\text { Conduct recruitment and selection of citizen panel and facilitator; } \\
\text { begin researching introductory paper. }\end{array}$ & B, G \\
\hline Month 3 & $\begin{array}{l}\text { Finalize composition of citizen panel, selection of facilitator, write } \\
\text { introductory paper. Contact prospective presenters. }\end{array}$ & B, F, G \\
\hline Month 4 & $\begin{array}{l}\text { Send introductory paper to citizen panel; work with facilitator to } \\
\text { prepare working script for Meeting 1. }\end{array}$ & D, G \\
\hline Month 5 & Hold Meeting 1. & E, G \\
\hline Month 6 & Hold Meeting 2. & E, F, G, H \\
\hline Month 7 & & E, F, G, H \\
\hline Month 8 & Hold Meeting 3; distribute consensus report. \\
\hline
\end{tabular}

\section{KEY PLAYERS}

Described below are the key players in the consensus workshop process: Advisory Committee, Project Staff, Facilitator, Citizen Panel, Resident Expert(s), Technical and Scientific Professionals, Media and Others.

\section{Advisory Committee}

The function of the Advisory Committee is to provide both technical and political support to the project managers. We recommend a 4-6 person group of individuals who have either strong technical knowledge of the issue or in-depth understanding of the economic, social, and political characteristics of the communities affected by the issue, from which the citizen panel is recruited. Finding members with diverse backgrounds will strengthen the effectiveness of the Advisory Committee. Depending on the issue of concern, including members from both public and private 
sectors, from research and practice, and with an understanding of regional, racial, and other community differences should be a priority.

\section{Project Staff}

We recommend a staff of at least 3 project staff for a well-managed process. The project staff are responsible for organizing and participating in each stage of the consensus workshop process, from selecting the Advisory Committee to distributing the final consensus report (see Appendix A). The most critical tasks to be divided among the project staff are as follows:

- establish a liaison between the entity commissioning the consensus workshop and all others involved;

- convene the Advisory Committee and organize its meetings;

- recruit and select citizen panel members;

- $\quad$ handle all meeting logistics for the consensus workshop;

- prepare and provide all citizen panel resources;

- $\quad$ organize, manage, and participate in all meetings of the consensus workshop;

- assist the citizen panel in writing the consensus report;

- finalize and distribute the consensus report; and

- work with the media and other interested parties to communicate about the workshop.

\section{Facilitator}

The consensus workshop requires an experienced, professional facilitator. Criteria for selection of the facilitator should include:

- neutrality on the issue of concern, yet enough familiarity with the issue to be able to understand the technical information presented and assist the citizen panel in discussing the information;

- skill in all types of facilitation techniques, including creating a confidential and "safe" environment, keeping a group on task, encouraging participation from all group members, managing disruptions, and bringing the group to consensus;

- energy and ability to work long hours over 2-3 days at a time;

- willingness to work as a team with the project staff; and

- $\quad$ availability for the entire period of the consensus workshop.

The facilitator is involved in the workshop process beginning approximately one month before the first meeting of the citizen panel. The facilitator needs to read and understand all resource materials provided to the citizen panel and she/he is responsible for preparing a working script (see Appendix B) for each meeting of the workshop. The importance of having an excellent facilitator cannot be overemphasized; this individual sets the tone for how productive and effective the workshop will be.

\section{Citizen Panel}

The citizen panel is composed of 10-14 people who have a commitment to learning about the issue of concern. Key characteristics of panel members are that they have little familiarity with and no expertise in the issue/technology of concern, and they reflect the diversity of the communities from which they have been selected. The goal of the citizen panel is to write a consensus report based on the questions they formulate as a group and the information they receive during the workshop meetings. 


\begin{abstract}
"Resident Expert(s)"
We recommend involving one or two "resident experts" in the entire consensus workshop. The role of the resident expert is to be available to provide clarification to the citizen panel throughout their meetings and while they write the consensus report. Two "resident experts" allow for one person who has significant knowledge of the technical aspects of the issue of concern and one who understands the economic, social, and political factors affecting the issue. Individuals in either role must have the ability to present a balanced view of the issue; articulating all sides of any debate of the issue. Resident experts may be selected from the Advisory Committee and they may be tapped to present information to the citizen panel, especially in the form of introductory information that presents many facets of an issue.
\end{abstract}

\title{
Technical and Scientific Professionals
}

In order to present the very best information to the citizen panel, technical and scientific professionals are scheduled to make presentations during the workshop meetings. A key aspect of the consensus workshop approach to public involvement is the fact that the citizen panel decides what questions need to be answered and, thereby, sets the course for what information is provided. Through its questions, the citizen panel determines how many and what types of professionals should be called upon to make presentations during the workshop. The likely number of presenters is from 6-10; the fields they represent range from scientific and engineering to political and educational.

\section{Media and Others}

A variety of reasons may exist for informing the media of the consensus workshop. The workshop itself may have been initiated to address an issue currently covered by the media. Just as importantly, once convened, citizen panel members may have an interest in letting their communities know about their efforts. In fact, the citizen panel may be interested in writing a press release to distribute to the media. The project managers (and facilitator) should be prepared to discuss involvement of the media with the citizen panel and/or respond to inquiries from the media, should they arise. This is true regarding other interested outside parties also. Such parties may include federal and state government agencies, local government, university researchers, private consultants, etc.

\section{MAJOR PROCESSES}

The consensus workshop is comprised of 10 major processes: Advisory Committee Meeting(s); Citizen Panel Recruitment and Selection; Selecting Location, Venue, Dates, and Times; Preparing for the Consensus Workshop Meetings; Managing the Meetings; Identifying and Scheduling the Technical and Scientific Professionals; Providing Resources to the Citizen Panel; Writing the Consensus Report; Communication; and Distribution of the Consensus Report. Each is described below.

\section{A. Advisory Committee Meeting(s)}

We recommend at least one meeting of the Advisory Committee in order to provide all members with an overview of the consensus workshop: its purpose, the process, and expected outcomes. This meeting should occur very early in the workshop planning process so that the project staff can 
take advantage of the perspectives and ideas of the Advisory Committee members. Specifically, members may offer the following:

- up to date information on and current status of the issue;

- a list of possible questions the citizen panel may ask;

- names of technical and scientific professionals who may be tapped as presenters;

- interest in serving as "resident experts;" and

- ideas for when, where, and how to hold the workshop.

\section{Strategies for Working with the Advisory Committee}

- Arrange a half- or three-quarters-day meeting that includes a meal and gives Advisory Committee members an opportunity to get to know one another and develop an interest for the workshop.

- Provide members with an explanation of the consensus workshop approach, a description of the role of Advisory Committee, a draft timeline for the workshop; contact information for the Advisory Committee members and the workshop staff; and any materials already prepared for the workshop.

- Be prepared to negotiate an honorarium or pay for Advisory Committee members.

- After an Advisory Committee meeting, keep members informed of major steps in the workshop process through e-mail and/or the workshop Web site.

\section{Equipment Needed for Meeting with the Advisory Committee}

- Packet with agenda and materials described under Strategies above.

- Flip chart and markers to capture member ideas.

- Laptop computer to record minutes.

\section{Outcomes}

- A group of professionals who support the workshop.

- Greater understanding of the issue/technolog.;

- A list of possible technical and scientific presenters for the workshop.

\section{B. Citizen Panel Recruitment and Selection}

Careful recruitment and selection of the citizen panel is critical to the success of the consensus workshop. The process must be handled with accuracy and fairness. Timely communication with applicants and those who are selected to serve on the panel is essential. We recommend that one staff person serve as the contact for those responding to the recruitment. Interested persons should be able to reach the contact person by telephone. The main stages of recruitment and selection are as follows:

1. Identify the community(ies) from which citizen panel members will be recruited.

2. Establish screening criteria (see Appendix C).

3. Consider how interested individuals can be reached; e.g., by newspaper, radio, public television, posted notices.

4. Write the recruitment advertisement (see Appendix D); ask the advertising sources for advice on where to place the display and how to word the ad to get people's attention.

5. Date stamp and file applications as they are received.

6. Select citizen panel members according to selection criteria. 
7. Notify applicants of selection/rejection .

Recruitment can be difficult to plan, depending on how well the project staff know the communities with which they are working. The initial recruitment may not be successful in generating a pool of applicants that is large enough to provide the diversity needed on the citizen panel. The overall process should allow time for an extended recruitment that gives the project staff a real choice among applicants to be selected for the citizen panel.

\section{Strategies}

- In the recruitment advertising, state the qualifications to participate (no expert knowledge of or experience with the issue/technology, desire to learn, availability on the scheduled dates); whether or not there is compensation (without stating the exact amount); how to apply; where to call for information.

- Proof read the advertisements carefully to avoid confusion and costly mistakes.

- Document screening decision.

- Don't leave applicants wondering about their status in the selection process; provide timely and direct information about where you are at each step of the selection process.

\section{Outcomes}

- A citizen panel whose members are pleased to be selected, are excited about the workshop, and have a basic idea of what to expect during the course of the workshop.

\section{Selecting the Location, Venue, Dates and Times}

Workshop meeting dates, times, and likely location(s) should be decided before recruitment of the citizen panel begins, so that applicants can decide whether or not they would be available to participate completely in the process. Beginning and ending times for meetings may be adjusted slightly and the decision to use a specific venue can be made later; however, the dates of the meetings should not be changed once panel members have been selected based on their availability on certain dates.

We recommend selecting a location and venue for the consensus workshop as soon as communities from which to recruit citizen panel members have been identified. Consider the following criteria when deciding on a place to hold the workshop meetings:

- convenience of travel to the location for citizen panel members, presenters, staff;

- perceived neutrality of the location;

- amenities offered by the venue such as overnight accommodations, catering, meeting facilities, and opportunities for outdoor activities and exercise; and

- cost.

\section{Strategies}

- Select a central location for all citizen panel members.

- Ask knowledgeable Advisory Committee members for their perspectives on various locations.

- Conduct an on-site visit of venues under consideration.;

- Ask individual citizen panel members if they have special needs for disabled access, food choices, smoking/non-smoking rooms, etc. 
- Be prepared to provide round-trip travel reimbursement to citizen panel members and presenters.

\section{Equipment}

- Make certain you have access to AV and other equipment for the meetings, including computer and projector for Powerpoint presentations, overhead projector, screen, extension cords, and flip charts and chart paper.

- Select a venue with a comfortable meeting room that includes enough space to seat all participants at a round or U-shaped table arrangement and space to break into small groups, windows with screens for darkening the room when necessary, and good (natural) ventilation.

\section{Outcomes}

- Securing a comfortable venue that is equally convenient to all panel members and that provides the broad range of amenities needed by a diverse group of people.

- For the project staff, finding a venue with professional staff who help make the consensus workshop a success.

\section{Preparing for the Consensus Workshop Meetings}

One foundational aspect of the consensus workshop approach is the influence the citizen panel has on the type of information presented and how learning for the panel members occurs. This translates into a process that requires a continual cycle of planning and assessment in order to meet the needs of the panel over the course of the workshop. Critical planning periods for the project managers and facilitator are before and after each meeting and after each meeting day. Planning before each meeting includes creating a working script (see Appendix B), agreed to by the facilitator and all staff involved. Ideas for the working script come from the debriefing that occurs after each meeting, when the staff and facilitator talk about what was accomplished, what the citizen panel has requested for the next meeting, and what must occur to move toward creation of a consensus report. It is also important to debrief and plan after each meeting day. Depending upon what happens each day, the facilitator and project staff may decide to revise the working script for the following day; the agenda for the citizen panel may be changed and printed out before the next day's activities.

\section{Strategies}

- Make sure the facilitator and project staff agree to the working script before activities begin on any particular meeting day.

- Before each meeting, develop a list of who will bring what materials and documents.

- Discuss who will play what role in facilitating and managing the meetings each day; include this information on the working script.

\section{Equipment}

- Portable computer and printer, and access to a copy machine.

\section{Outcomes}

- Shared understanding among facilitator and staff about how the meetings will be handled.

- Flexibility to respond to changing and/or unanticipated needs of the citizen panel. 


\section{E. Managing the Meetings}

One of the most powerful aspects of the consensus workshop is the potential it holds to engage and educate the citizen panel. In order to accomplish this, a variety of things must happen. Through the planning and facilitation provided by the project staff, citizen panel members must develop a commitment to the process and to the other panel members. The meetings must occur in a safe and open environment where individuals feel respected. The process must belong to the panel members; decisions and activities must reflect the feelings and desires of the panel, not the project staff. Information provided must be balanced, up-to-date, and accurate. Finally, the process has to be meaningful and enjoyable for the citizen panel.

\section{Strategies}

- Incorporate all types of activity into the working script; include exercises and opportunities to learn about each other, build trust, ask questions and get clarification, be productive, rest, and have fun.

- Be aware that the members of the citizen panel will have different learning styles; plan presentations and exercises that take different learning styles into account.

- Utilize both whole-group and small-group exercises and discussions.

- Use exercises and small-group assignments to provide opportunities for each citizen panel member to get to know/work with each other member.

- Plan for variety throughout a day's activities, including physical exercise, play or laughter, and breaks from all planned activity.

\section{Equipment}

- Props, novelty items, other things to use in exercises and games; table tents for names of both panel members and specialists.

\section{Outcomes}

- A citizen panel that is engaged, able to learn, and committed to the group.

\section{F. Identifying and Scheduling the Technical and Scientific Professionals}

For the consensus workshop project staff, identifying and scheduling the technical and scientific professionals is one of the most demanding aspects of the consensus workshop. Key to the success of the workshop is having the citizen panel decide what types of professionals they will hear from at each stage of the workshop. Specifically, for Meetings 2 and 3, the citizen panel decides, at the end of each previous meeting, what types of people (and, in some cases, which particular people) should be engaged for the next meeting. For the project staff, this means identifying and scheduling professionals to speak with only a few weeks lead time. Once identified, each presenter must be briefed on the purpose of the workshop and what information the citizen panel expects to receive. The project staff must also arrange for travel and accommodations for each professional presenter.

We recommend asking each presenter to participate for the entire day she/he is scheduled to make a presentation, so that all presenters conclude any given day with a panel discussion among themselves and the citizen panel. For many citizen panel members, this is where significant 
learning takes place; when professionals talk among themselves and all take questions from the citizen panel many of the more complex issues are addressed in depth. Citizen panel members prepare for the presenter panel discussion by breaking into small groups and developing questions to ask the presenters. It is also helpful to begin any meeting following a day of presentations by reviewing the information presented the day before.

\section{Strategies}

- Where possible, anticipate which particular professionals will be needed to speak and ask them to hold tentative dates on their calendars (Advisory Committee members can help identify key individuals likely to be of interest to any citizen panel.

- Use professional networks to find potential presenters; be direct about the need for speakers who are skilled in presenting complex information to non-technical audiences; (i.e., speakers who can explain complex ideas in non-technical terms without "speaking down" to people).

- Be prepared to negotiate honoraria or pay for professional presenters.

- Provide potential speakers with background information about the purpose of the consensus workshop, the role of the citizen panel, and the specific questions for which the citizen panel seeks answers.

- Talk with presenters about how they will make their presentation and what equipment is needed.

- Arrange to provide the citizen panel with copies of each presentation - if the presenter cannot provide a copy before the meeting, ask him/her to bring copies or panel members.

- Plan for the "resident experts" and/or the project managers to provide summaries of the previous day's presentations at the beginning the subsequent meeting day.

\section{Equipment}

- All AV equipment requested by presenters.

\section{Outcomes}

- Successfully arranging a series of speakers within a few weeks time;

- Providing professional presenters who increase the learning of citizen panel members.

\section{G. Providing Resources to the Citizen Panel}

The purpose of the consensus workshop is to educate the citizen panel about an issue so that they can produce a consensus report focused on the questions the issue raises for them. Doing this well requires two types of information: 1) frequent and timely communication about the workshop process and logistics, and 2) a broad range of materials about the issue of concern.

Citizen panel members should never have to wonder when, where, or how each meeting will take place. At least two weeks before each meeting, the project staff should send a summary description and itinerary to each person listing meeting dates, times, location, address, telephone number, hotel check-in/-out procedures, parking arrangements, etc. Citizen panel members should know where to call the project staff for any questions about the workshop logistics.

Knowing what information is needed related to the issue of concern requires sensitivity to ongoing and changing needs of the citizen panel for different types of information. Prior to Meeting 1 , 
citizen panel members need introductory information about the issue of concern. We recommend providing an introductory paper (see Appendix E), written by the project staff with assistance and review by the Advisory Committee. This allows the project staff to focus the issue for themselves and for the citizen panel as the process is initiated.

At the meetings themselves, citizen panel members should receive the following materials:

1. Loose-leaf notebook to hold all materials

2. Meeting agenda

3. Names and contact information for citizen panel members and project staff

4. Background information about the presenters

5. Copies of presentations for that meeting

Meeting 1 typically generates a broad range of questions from the citizen panel about the issue. As soon as possible after Meeting 1, but no later than two weeks before Meeting 2, citizen panel members should receive a typewritten copy of the minutes of Meeting 1, copies of other documents generated at Meeting 1, copies of additional background or educational materials, and, where possible, materials to read to prepare for new information to be presented in Meeting 2.

To the extent possible, Meeting 2 should focus the education process on aspects of the issue contained in the citizen panel's questions that will form the content of the consensus report. Citizen panel members should show some understanding of the technical aspects of the issue and be capable of learning about more complex aspects of the issue. As above, as soon as possible after Meeting 2, and no later than two weeks before Meeting 3, panel members should receive the minutes of Meeting 2, copies of other documents generated at Meeting 2, copies of additional background or educational materials, and, where possible, materials to read to prepare for new information to be presented in Meeting 3 .

Meeting 3 allows one day (Day 5) to provide the final types of information viewed by the citizen panel as necessary in order to write the consensus report, which takes place on Days 6-7. Resources needed by the citizen panel to write the consensus report are described in the section "Writing the Consensus Report" below.

\section{Strategies}

- Assign one project staff member to take minutes of each meeting using a laptop computer.

- To the extent possible, provide citizen panel members with new material prior to the upcoming meeting to allow panel members time to prepare and absorb the material.

\section{Equipment}

- Laptop computer(s).

\section{Outcomes}

- Frequent, timely communication with the citizen panel about the process.;

- Assisting the citizen panel members in accessing and absorbing new information. 


\section{H. Writing the Consensus Report}

Producing the written consensus report is an organizational challenge that requires careful planning by the project staff and the facilitator. Keys to success include:

1. establishing the role of the citizen panel in reaching consensus;

2. defining and discussing the concept of consensus;

3. writing the report "as you go;" and

4. organizing the writing process to include all panel members and still produce a complete document at the end of Day 7.

Early in the consensus workshop process (first part of Day 1) citizen panel members should be introduced to the notion of writing a consensus report. We recommend providing a draft charter (see Appendix F) on Day 1 that sets out the goal of the workshop, the roles and responsibilities of the members, and the benefits of participating. Members should be led through an exercise that provides them the opportunity to read the draft charter, discuss and revise it, and agree to a charter for the group. As part of this process, members should discuss the concept of "consensus" and find ways to think about it such as, "consensus means 'we can live with it'." We recommend establishing an expectation that panel members all will sign the final report, signifying that they have reached consensus.

Throughout the workshop, the facilitator and project staff should refer to the ultimate task of writing the consensus report. This initiates the process of writing the report "as you go" through the workshop. In Meeting 1, citizen panel members have the task of developing questions, the answers to which will form the content of the consensus report. During Meeting 2 the panel should participate in exercises that involve developing an outline for the report, beginning to draft sections of the report for which members are prepared (e.g., "defining the issue" or "describing the workshop process"), and discussing how to organize the writing process. Prior to Meeting 3 , the project staff can pull together information that may assist the report writing, given the outline already in place. Sections of the report may consist of materials or documents already produced by the panel such as the list of questions or the draft sections mentioned above. Panel members should begin Meeting 3 having a draft copy of the report that, while sketchy, contains sections that have been written or drafted in prior exercises.

The last two days of Meeting 3 (Days 6 and 7) consist of writing and completing the consensus report. Having discussed the writing process in Meeting 2, panel members know how the writing will be organized. We recommend a process that moves back and forth between small groups drafting different sections of the report to the whole group discussing and revising sections as they are drafted. The facilitator and project staff play critical roles as scribes, encouraging members within small groups to get ideas written down and typing the small groups' ideas on laptop computers. Using computers allows the facilitator to project the draft sections on a screen for review and discussion by the whole group. Changes can be viewed by the whole group as they are made on the computer. The final draft copy can be viewed and printed from the computer file. Copies of this final draft can be signed (on a separate piece of paper) by all panel members to signify consensus. 
After the workshop is concluded, with a final draft completed, the project staff can provide the editorial changes needed to make the report accurate and readable. The signature page can be inserted in the final document and mailed to the citizen panel members.

\section{Strategies}

- Take as much time as is necessary to make the citizen panel comfortable with the concept and goal of consensus.

- Identify a way to signify consensus in the final report, such as including a signature page.

- Lay out a detailed plan in the working script for writing and completing the consensus report.

- Write the report "as you go," using exercises throughout the workshop to produce summaries/descriptions that might inform the final report.

- Provide the citizen panel with copies of a sample consensus report.

\section{Equipment}

- Laptop computers, computer projector, screen

\section{Outcomes}

- By the end of Day 7, a final draft signed by all citizen panel members.

\section{Communication}

Clear, direct, and frequent communication with the citizen panel is essential. We recommend using both mailed letters and the telephone to make certain all panel members receive all of the information provided for the workshop. Computer e-mail and a project Web site may be convenient for some panel members; however, it is unlikely, at this writing, that all members will have access to a computer or will refer to their computers on a regular basis.

One feature of the consensus workshop is that citizen panel members come to feel a sense of responsibility to their communities related to the issue they are exploring; they may wish to inform their neighbors and communities about the work they are doing. One way to do this is to distribute a news release (see Appendix $\mathrm{G}$ ) to the local media. The project staff can draft a release and ask for review and input from the panel members. Panel members may also have ideas for where and to whom to distribute the information.

Given the nature of the issues typically considered in the consensus workshop approach to public involvement, entities and individuals not directly involved may have interest in the process and outcomes of the workshop. From the beginning of the planning process, project managers should consider what federal and state agencies, private companies or interests, and community groups may have an interest in discussion of the issue of concern. Telephoning or e-mailing possible interest groups can build support for the process and, at least, avoid potentially troublesome misunderstandings about the purpose and outcomes of the process.

The Web is an excellent tool for communicating with potentially interested parties about the consensus workshop. 


\section{Strategies}

- Be prepared to discuss with the citizen panel the extent to which the process will be shared with the public.

- Be clear with the citizen panel members and others what outcomes are anticipated.

\section{Outcomes}

- Reduce criticism of/generate support for the workshop outcomes.

\section{J. Distribution of the Consensus Report}

Distribution of the consensus report will depend upon the original goals of holding the workshop; however, citizen panel members are likely to question how their work will be used. The project staff and facilitator should provide clear information about the intentions of the sponsor and the anticipated use of the consensus report. This information also can be included in the citizen panel charter. Make certain every citizen panel member receives a final copy of the consensus report.

\section{SPECIAL CONSIDERATIONS}

\section{Time Pressures}

Timing becomes a critical element once the consensus workshop begins and, in particular, between meetings. As mentioned earlier, a fundamental aspect of the consensus workshop is the role the citizen panel plays in determining the questions that drive the writing of the consensus report and what information is needed to address those questions. The project managers may not know just what should be arranged for Meeting 2 or 3 until after Meeting 1 or 2, respectively. This may allow only a few weeks to identify and schedule certain presenters or find and provide specific information or the upcoming meeting. Project managers should keep the timing factor in mind when planning their work schedules for the consensus workshop.

\section{Citizen Panel Stipends and Reimbursement}

Serving as a citizen panel member in the consensus workshop requires a significant commitment from the individuals involved. The meetings themselves total approximately 60 hours including the time spent in meals together. Travel to and from the workshop location may take from several hours to many hours over the course of the entire workshop. With the goal of involving a diverse group of people who are motivated to spend many hours learning as part of a group process, we believe it is essential to compensate the panel members by paying a stipend for their participation. For organizations able to do so, we suggest calculating the stipend by taking the number of hours of participation times the minimum wage (or more) in the state. We also recommend reimbursing panel members for the cost of car travel to and from the workshop location.

\section{Budget}

Expenses for consensus workshops may vary markedly depending upon such things as number of panel members, number of professionals who require pay, type of venue, amount of travel time necessary for staff, panel members and presenters, etc. The following expense categories are likely to be relevant for creating a budget for a consensus workshop. 


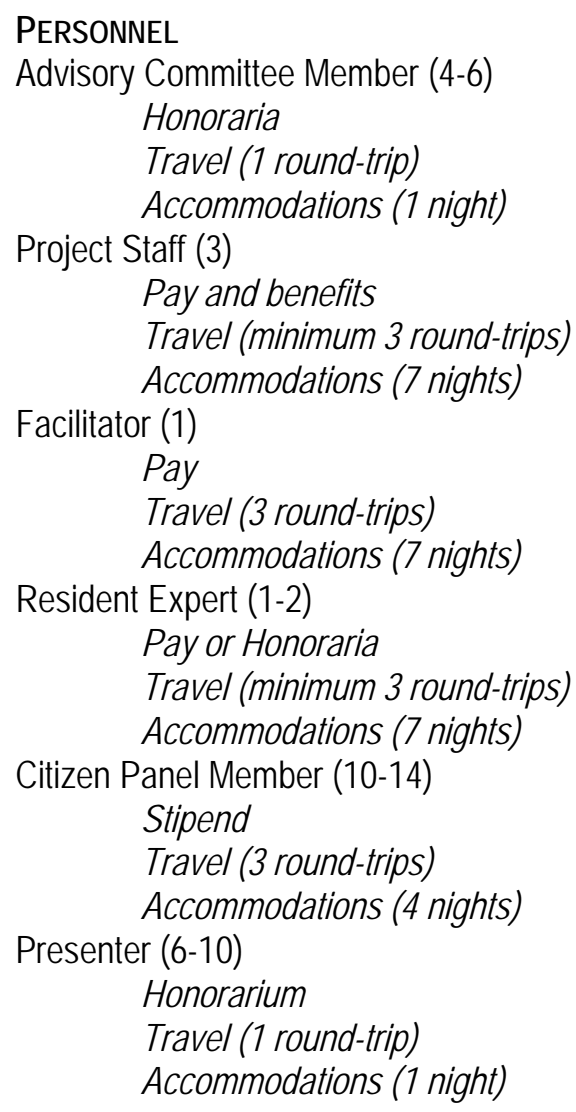

\author{
Advisory CommitTeE MeEting \\ Materials and Supplies \\ Food \\ Citizen Panel Recruitiment \\ Advertising \\ Postage \\ WORKSHOP VENUE \\ Meeting Room (minimum 1 per meeting \\ =3) \\ Equipment \\ Meals (total $=15$ ) \\ Day 1 - lunch/dinner \\ Day 2 - breakfast/lunch \\ Day 3 - lunch/dinner \\ Day 4 - breakfast/lunch \\ Day 5 - lunch/dinner \\ Day 6 - breakfast/lunch/dinner \\ Day 7 - breakfast/lunch \\ Snacks (minimum 1 per day $=7$ ) \\ General Operations \\ Celebration (on Day 7) \\ Materials and Supplies \\ Printing and Copying \\ Postage \\ Telephone
}

\section{SUMMARY}

The consensus workshop described in this manual is a new approach to public involvement derived from the consensus conference model used in the U.S., Europe, and Australia. The consensus workshop focuses on educating a group of citizens about a technology issue so that they are able to produce a consensus report that addresses their questions and concerns about the issue. The manual is written to provide clear and thorough instructions on how to utilize this approach successfully. We invite comments and suggestions for revising this manual so that is will be useful to all who are interested in the consensus workshop approach to citizen participation.

\section{APPENDICES}

The appendices contain samples of key documents or tools used in the 2002 Bioremediation Consensus Workshop funded by the Department of Energy, NABIR program.
A. Consensus Report (see Appendix F of Final Report)
B. Working Script (see Appendix D of Final Report)
C. Screening Criteria
D. Recruitment Advertisement (see Appendix B of Consensus Report)
E. Introductory Paper (see Appendix B of Final Report)
F. Charter (see Appendix D of Consensus Report)
G. News Release (see Appendix E of Consensus Report) 


\section{Appendix C: Screening Criteria}

Screening criteria were used to select a diverse group of panel members with a broad range of backgrounds, characteristics, and attitudes. That is, the project staff selected individuals who, together, represented a wide range in age, amount of education, type of occupation, etc. The total set of criteria were:

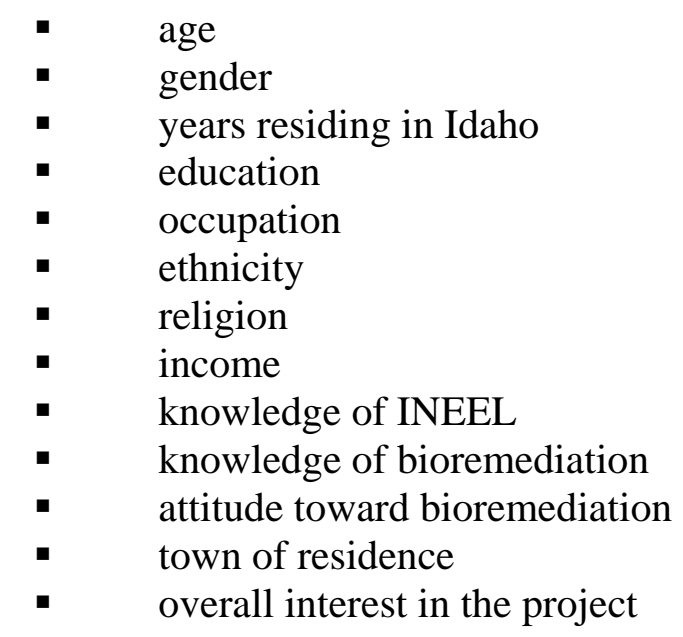




\section{Appendix B}

\section{INTRODUCTION TO BIOREMEDIATION}

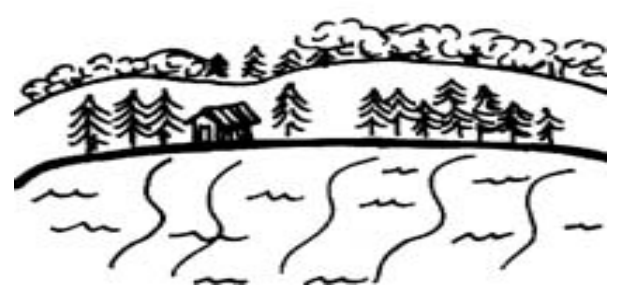

at U.S. DEPARTMENT OF ENERGY SITES

An introductory paper for lay panel members

Bioremediation Consensus Workshop 2002 


\section{Table of Contents}

1. Why is it necessary to clean up DOE sites?................................................... 2

2. What is bioremediation? .......................................................................... 3

3. How does bioremediation work? ................................................................ 3

4. Will bioremediation work at DOE sites? ....................................................... 5

5. What kinds of methods are currently used to clean up contamination? ........ 7

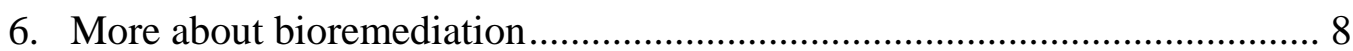

6a. Ex situ and in situ bioremediation methods ...................................... 8

6b. Accelerated in situ bioremediation ................................................... 9

6c. Intrinsic bioremediation............................................................... 9

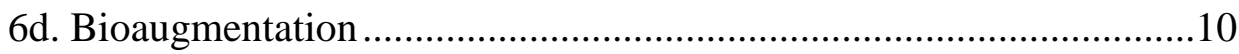

6e. Phytoremediation............................................... 10

6f. Using genetically engineered microorganisms (GEMs) .....................10

6g. Ex situ bioremediation .......................................................................11

7. Aquifers and Contaminant plumes................................................................11

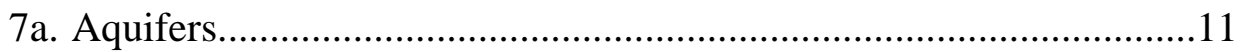

7b. Contaminant plumes .........................................................................13

8. Site Example: Bioremediation at INEEL .......................................................14

8a. The eastern Snake River Plain Aquifer................................................15

8b. Plans for bioremediation at Test Area North (TAN) ...........................16

8c. Comprehensive aquifer cleanup.......................................................17

9. Summary of Cleanup Approaches ………………………….......................18

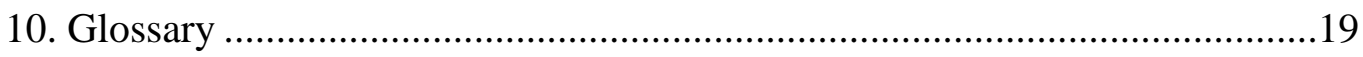

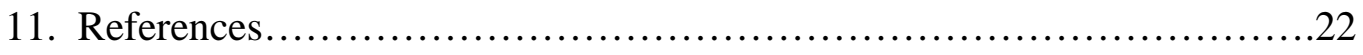




\section{Why is it necessary to clean up Department of Energy sites?}

For more than 50 years the United States has used nuclear energy for both peaceful and military purposes. Nuclear research and operation activities at U.S. Department of Energy (DOE) sites have left behind contaminants that result in risks to human health and the environment. With the end of the Cold War threat in the early ' 90 s and the shutdown of all nuclear weapons production reactors in the United States, the DOE has shifted its emphasis to the cleanup and restoration of these contaminated sites.

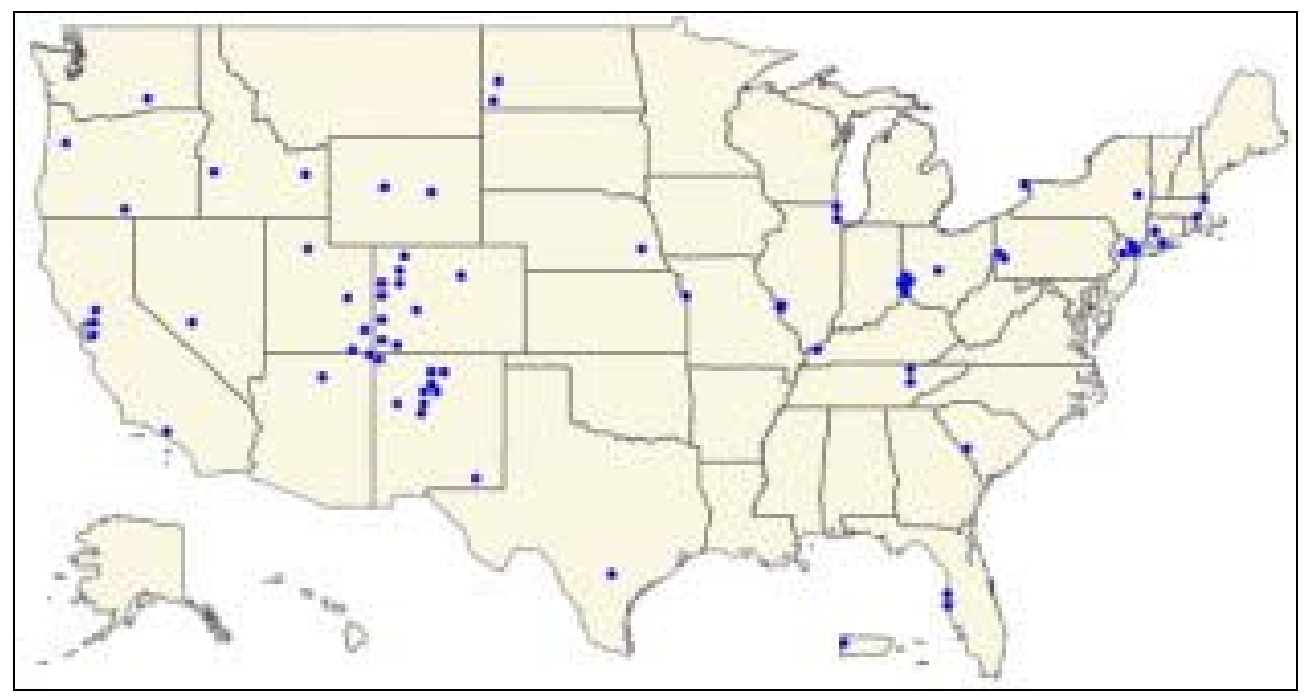

Figure 1: Department of Energy Sites in the United States

Figure 1 shows the DOE installations contained in the Cleanup Criteria/Decision Document (C2D2) database. A single DOE installation can have 30 or more individual cleanup sites, and these sites themselves can contain several individual cleanup areas ("subsites").

Overall, the DOE must identify, treat, and dispose of hazardous and radioactive waste at more than 120 sites in 36 states and territories. This includes 475 billion gallons of contaminated groundwater", 75 million cubic meters of contaminated sediments, and 3 million cubic meters of leaking waste buried in landfills, trenches, and spill areas. Budgets for these activities just for the next 10 years are estimated to exceed $\$ 60$ billion. The DOE cleanup of the Cold War legacy is the largest program of its kind ever undertaken by the United States.

To meet cleanup objectives, the DOE is looking at many different kinds of cleanup - or remediation - technologies. One of these cleanup technologies is called bioremediation.

\footnotetext{
${ }^{*}$ Words in italics are defined in the glossary, page 19.
} 


\section{What is bioremediation?}

Bioremediation is a treatment for the cleanup of hazardous waste that uses bacteria to break down or change contaminants into less toxic or nontoxic substances. Microscopic "bugs" or microbes that live in soil and groundwater can consume certain harmful chemicals. One kind of bioremediation, used for organic chemicals such as oils and gasoline, involves microbes using contaminants as a "food source;" in this way, the contaminants are changed into water and harmless gases such as carbon dioxide.

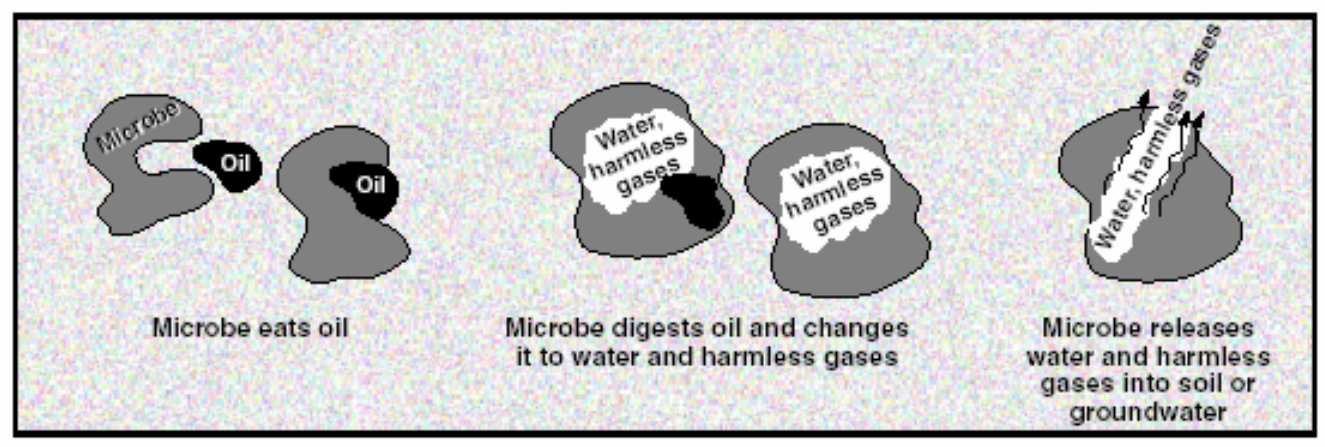

Figure 2: Bioremediation Process

\section{How does bioremediation work?}

In order for microbes to clean up harmful chemicals, the right temperature, food sources, and nutrients (substances or elements that are essential to the growth of the microbe) must be present in the soil and groundwater. These conditions allow the microbes to grow and multiply - and "eat" more chemicals. When conditions are not right, microbes grow too slowly or die. One way to get the right food sources and nutrients to microbes is to pump air or nutrients underground. Different kinds of added substances may be used depending on the circumstances. For example, molasses is one substance that has been added to help the microbes grow underground. Sometimes microbes are added if enough aren't already there; this is called bioaugmentation and is described later. With the right temperature and amount of oxygen and nutrients, microbes can do their work to "bioremediate" harmful chemicals.

In bioremediation, bacteria facilitate chemical reactions that would not occur without the bacteria and their special enzymes or organic catalysts. These chemical reactions result in changes or transformations of chemicals; for example, bacteria can transform sugars into carbon dioxide. Bioremediation can create a mix of chemicals that is less hazardous than the mix before transformation.

Transformation occurs when there is a shift of the number of electrons in each chemical in a reaction. The number of 
electrons before and after a transformation must be the same; in other words, electrons are "transferred" as they move from chemicals that are electron donors to chemicals that are electron acceptors. The bacteria in bioremediation simply help the electron transfer to take place.

Chemicals that easily give up electrons are called electron donors; they serve as the "food" in bioremediation. Electron donors are the source of energy for organisms like bacteria. Many different organic chemicals, such as sugars, amino acids, and hydrocarbons, and some inorganic chemicals such as ammonia or hydrogen, can function as electron donors.

Chemicals that easily accept electrons are called electron acceptors; in bioremediation, they are associated with respiration. For example, bacteria can use oxygen from air as an electron acceptor. Other common electron acceptors are nitrate, sulfate, and carbon dioxide.

In bioremediation, hazardous chemical(s) may act in one of three ways when it comes to these chemical transformations. One, the chemical of concern may act as an electron donor. Gasoline cleanup is one example. In order to clean up gasoline with bioremediation, an electron acceptor such as oxygen needs to be added to complete the transformation of gasoline into carbon dioxide.

Two, the chemical of concern may act as an electron acceptor. For example, when using bioremediation to clean up tricholoroethylene or TCE, an electron donor or "food" such as molasses is used to transform the TCE into

dichloroethylene or DCE.

In the third case, the chemical of concern may be transformed through cometabolism. In this case, a chemical reaction occurs between an electron donor and an electron acceptor, neither of which are the chemical of concern. However, the bacteria that grow while such a reaction is occurring can transform the chemical of concern as a "side reaction." For example, TCE is transformed by cometabolism through bacteria that use butane as an electron donor or food, with oxygen as an electron acceptor or respiring chemical.

The right conditions for bioremediation cannot always be achieved underground. In these situations, soil might be dug up and cleaned above ground where extra heat or soil mixing may help improve conditions. After the soil is dug up, nutrients important for the growth of the microbes often are added. Oxygen also may be added by stirring the mixture or by pumping air through it, resulting in aerobic ("with air") treatments. Some microbes work better without oxygen. Anaerobic treatment takes place when organisms use chemicals such as nitrate, sulfate, or carbon dioxide instead of air for respiration.

Sometimes mixing soil can cause harmful chemicals to evaporate before the microbes can "eat" them. To prevent these chemicals from polluting the air, soils are mixed inside a special tank or building and chemicals that evaporate are collected and treated.

Microbes can help clean polluted groundwater as well as soil. To do this, 
wells are drilled and some of the groundwater is pumped into tanks. Often, the water is mixed with nutrients and air before it is pumped back into the ground. The added nutrients and air help the microbes bioremediate the groundwater. Nutrients, food, and air also can be mixed with water in the ground through carefully-placed wells. Once harmful chemicals are cleaned up and microbes have "eaten" their available "food," the microbes die and naturally decompose.

Whether or not bioremediation occurs, and how much time it takes to bioremediate a site depends on several factors:

\section{Will bioremediation work at DOE sites?}

Bioremediation has been successfully used on organic chemicals, like fuels and solvents, which contain primarily carbon and hydrogen atoms. Scientists are now looking at the possibility of using bioremediation on inorganic chemicals like radionuclides (radioactive chemicals) and metals.

A significant portion of the contamination at DOE sites consists of radionuclides and metals and the DOE is especially interested in whether or not bioremediation can be used to clean up such contaminants. The cleanup of radionuclides and metals with bioremediation is not understood as well as technologies for the cleanup of organic contaminants, so the DOE is placing special emphasis on this topic.

Radioactive and metallic contaminants at DOE sites include cesium, chromium,
Types and amounts of harmful chemicals present

$>$ Whether the right balance of food, nutrients, and other substances can be maintained where the harmful chemicals are located

$>$ Size and depth of the polluted area

$>$ Type of soil and the conditions present

$>$ Whether cleanup occurs above ground or underground

$>$ Whether the right microbes are present at the site

$>$ Whether food sources, nutrients, or additional bacteria can be easily added to the site.

lead, mercury, plutonium, uranium, strontium, and technetium. All are metallic elements and very toxic. In addition, cesium, plutonium, strontium, technetium, and uranium can be extremely radioactive.

The bioremediation process described above, where microbes degrade oils or other organic chemicals and change them to water and carbon dioxide, doesn't occur for metals and radionuclides. Metals and radionuclides cannot be biodegraded. However, microorganisms can interact with radionuclides and metals and transform them from one chemical form to another. This transformation may result in increased mobility of the contaminant and allow it be more easily flushed from the site. In other cases, the opposite may occur and the contaminant will be immobilized in the ground, thus 
reducing the risk to humans and the environment. Both kinds of transformations present opportunities for bioremediation of metals and radionuclides - either to keep them in place or to speed up their removal.

* Inorganic chemicals include metals and nitrogen-containing compounds such as nitrate. The behavior of some inorganic chemicals in the environment is not understood as well as the behavior of organic chemicals.

* Some inorganic chemicals, such as metals, cannot be destroyed. They can only be transformed to other forms of the metal.

* While many metals are essential to life, practically all are toxic in excessive quantities, and some are toxic in very small quantities. Some forms of metals are extremely stable in the environment and retain the potential to cause harm essentially forever.

* Symptoms of human exposure to unsafe levels of metals can be complex. For example, exposure to unsafe levels of chromium can cause liver, kidney, circulatory, nervous system and skin damage, and possibly lung cancer. Exposure to unsafe levels of lead can cause mental problems, circulatory and kidney damage, and cancer. Young children, infants, and fetuses are particularly vulnerable to the negative health effects caused by lead. Exposure to unsafe levels of nitrate can cause damage to the spleen and can interfere with an infant's ability to carry oxygen in the blood.

* The term "nitrate" is used to refer to nitrate and nitrite, which are simple compounds of oxygen and nitrogen. Nitrates are a byproduct of many industrial processes, a break-down product of animal waste, and a common fertilizer. Nitrates are also the end product of breakdown pathways for many nitrogen-containing chemicals.

* Metals in the environment are commonly absorbed and concentrated by plants and animals. This can be dangerous to humans if they eat the plants and animals. On the other hand, this characteristic is useful to some environmental restoration projects. After plants absorb metals that contaminate soils, the plants can be harvested and disposed of in a way that removes the absorbed metals from the environment. (This cleanup approach, called phytoremediation, is discussed later.)

Figure 3: Some Facts about Inorganic Chemicals (such as metals) 
* Radionuclides are radioactive forms of elements; for example, iodine-129 is a radioactive form of iodine. Tritium is a radioactive form of hydrogen that is usually found as a component of water (water is composed of hydrogen and oxygen).

* Radionuclides emit radioactivity or decay at predictable rates called half-lives. A half-life is the time it takes for one-half of the atoms in a quantity of a radionuclide to decay. Starting with the original quantity, 50 percent of the atoms have decayed after the first half-life, 75 percent after the second half-life, and so forth. After 7 half-lives, less than 1 percent of the radionuclide remains in its original form, and the rest has decayed either into another radionuclide or a nonradioactive substance.

* Radionuclides can be ingested as inhaled dust, or in food and water. Low doses of radiation, such as what might be found in contaminated drinking water, can damage the genetic material in cells and lead to cancer.

* In soils and rock, most radionuclides are not very mobile, but they can be transported significant distances by water and other liquids. In other environments, like the air, most radionuclides quickly form compounds with oxygen and other common elements.

* Tritium is a radioactive form of water with a relatively rapid rate of decay. There is no practical cleanup method that can separate tritium-containing water from ordinary water. After 86 years, less than 1 percent of the original radioactivity in a quantity of tritium-containing water will remain.

* Other radionuclides of concern are cesium-137 and strontium-90.

Figure 4: Some Facts about Radionuclides

\section{What kinds of methods are currently used to clean up contamination?}

When the contamination is located near the surface, then several methods of cleanup are commonly used. Such methods often involve digging up the contaminated soil using heavy construction equipment such as backhoes and bulldozers, and then either disposing of the contaminated soil at an approved landfill (this is called "dig and haul”), incinerating the contaminated soil, or treating the contaminated soil with chemical or other means and returning the cleaned soil to the site.

However, if the contamination is located deep in the ground and has reached the underground water, then other methods must be used. The kinds of contamination to which the DOE is interested in applying bioremediation technologies are generally deep underground. Methods typically used for deep contamination usually involve pump-and-treat technologies. Pumpand-treat is where the contaminated groundwater is pumped out of the ground, treated with chemical or other means to remove the contamination, and then the cleaned water is returned underground. For example, groundwater that contains heavy metals can be pumped to the surface. At the surface, precipitation separates heavy metals from the water by changing dissolved 
heavy metal contaminants into a solid form that can be separated from the water. The solids are removed from the water and the clean water is then pumped back into the ground and the collected metals are properly disposed of.

Some disadvantages of pump-and-treat are that it can take a long time, and bringing the contaminants up to the surface can increase health and safety risks for cleanup workers and the public.

It is also possible to clean up contaminated soils and groundwater without bringing them out of the ground, using in situ methods. Webster's Dictionary defines in situ as "in place; in the natural or original position or place." In situ bioremediation refers to belowground methods applied at the site of contamination.

One in situ cleanup method is placing a "barrier" or filter in the ground through which the contaminated groundwater passes. The barrier can be either chemical or physical. For example, one type of barrier is an iron "Brillopad" where the iron reacts with the contaminant to change it into a less toxic or nontoxic form. When metal contaminates pass through the iron barrier, they react with the iron and become less toxic. This kind of in situ technology is difficult if the contamination is very deep underground.

\section{More about bioremediation}

\section{6a. Ex situ and in situ bioremediation methods}

While in situ means "in place," ex situ means "in a position other than the original one." There are a number of $e x$ situ and in situ bioremediation methods currently available. The DOE is most interested in in situ bioremediation for several reasons. In situ bioremediation offers a way of treating contaminants that are widely dispersed in the environment, occur in low concentrations, or are otherwise inaccessible. It is more cost effective than ex situ techniques because no pumping or excavation is required. Also, in situ bioremediation may be less hazardous to workers and the public, because there is no exposure to the contaminant during treatment, a consideration because of the mixing of metals and radionuclides with organic contaminants at DOE sites. This mixing has resulted in modification of the contaminants' transport and toxicity properties, which often imposes an increased health risk to workers and the public. For this reason, the DOE is most interested in in situ applications of bioremediation. However, the main disadvantage to in situ bioremediation is that it can be difficult to contain and control. 


\section{6b. Accelerated in situ bioremediation}

Accelerated in situ bioremediation, also known as biostimulation, is the addition of nutrients, oxygen, or substances to increase the number or activity of naturally occurring microorganisms available for bioremediation. These components can be added in either liquid or gas form.

Problems that can occur with accelerated in situ bioremediation include difficulty

\section{6c. Intrinsic Bioremediation}

Intrinsic bioremediation occurs in situ and relies on the already-existing naturally occurring biological processes in the ground. Intrinsic bioremediation was first noticed a number of years ago at sites of petroleum contamination. The contaminants of concern were degraded without human intervention. Nothing extra was added to the ground. The pollutants were being biodegraded by the microorganisms at rates fast enough to stop or reduce contaminant spread.

Intrinsic bioremediation, though it occurs without human intervention, requires long term monitoring to make sure that the predictions for breakdown of the contamination are really happening.

Advantages of intrinsic bioremediation (compared to accelerated in situ bioremediation) are:

Less environmental intrusion because few surface structures are required.

$>$ Can be used on all or part of a given site, depending on site associated with the delivery of nutrients. Sometimes the injection wells get plugged up with bacteria that feed on the nutrients. Also, it can be very difficult to achieve the proper balance of food, nutrients, and microbes underground to create just the right conditions for the contamination to be reduced or eliminated.

conditions and cleanup objectives.

$>$ Can be used in conjunction with, or as a follow-up to, other remedial measures, including ex situ measures.

$>$ Lower cost.

Disadvantages of intrinsic bioremediation (compared to accelerated in situ bioremediation) are:

Longer time frames may be required to achieve remediation objectives, compared to accelerated bioremediation or other active remediation technologies.

$>$ Procedures for determining the feasibility of intrinsic bioremediation may be complex and costly.

$>$ Can produce chemicals that are more toxic than the original contamination.

$>$ Long term monitoring will generally be necessary. 
$>$ Institutional controls such as land use restrictions may be necessary to ensure long term protection.

$>$ Potential exists for continued contamination migration, and/or transfer of contaminants to other places.

$>$ Conditions underground, like water and geologic conditions, could change over time, resulting in renewed mobility of the contaminants.

$>$ More extensive education and outreach efforts may be required in order to gain public acceptance.

\section{6d. Bioaugmentation}

Bioaugmentation is adding microorganisms to the contaminated site. Just adding the microorganisms to the site has not been very effective in underground environments, but

\section{6e. Phytoremediation}

Phytoremediation is the use of plants to remediate contaminated soils that surround and are influenced by plant roots and their associated microbial communities. Phytoremediation technology has several advantages. It is inexpensive compared to conventional technology and could prove cost
Whether accelerated or intrinsic in situ bioremediation is used at a particular site depends on the nature of the contamination, the goals of the remediation project, and the economics of each option. The rate of contaminant degradation is typically slower for intrinsic bioremediation than for accelerated bioremediation because the concentration of bacteria is much greater in accelerated bioremediation. Thus, natural attenuation typically takes longer to complete. Accelerated in situ bioremediation usually provides a faster solution, but has a much greater investment in materials, equipment, and labor.

microorganisms can be "cultivated" in containers above-ground and then continuously injected underground for in situ treatment, or they can be used for above-ground, ex situ treatment.

effective for soils in which near-surface contamination is dispersed over broad areas. The disadvantages of phytoremediation are that it involves slow rates of transformation and it can only bioremediate surface soils and water.

\section{6f. Using genetically engineered microorganisms (GEMs)}

Researchers are beginning to investigate genetically engineered microorganisms (GEMs) for use in bioaugmentation. Theoretically, GEMs could be developed to degrade or transform compounds that contain metals and radionuclides. However, the application of genetic engineering technology for use in the 
environment remains controversial. This is partly due to the concern that GEMs are not "natural" and may persist in the

\section{6g. Ex situ bioremediation}

Landfarming is the mixing of waste with surface soil over a tract of land. This technique has been used extensively to treat sludges from domestic sewage and industrial processes. The wastes are applied to soil surfaces as sludges or watery slurries, and the mixture is aerated through tilling. Landfarming holds a number of possibilities for bioremediation of radionuclides and metals by mobilizing, immobilizing, or biotransforming radionuclides and metals. A disadvantage of landfarming is its relatively high cost. environment, potentially causing an environmental upset.
Slurry bioreactors and soil-washing equipment are commonly used to treat excavated sediment to which water is added. Slurry bioreactors are stirred tanks within which biodegradation or biotransformation takes place in an aerobic environment (an environment in which air is present). Soil washing, which can be used in conjunction with the slurry process, is primarily a means of reducing the volume of contaminated sediment. The disadvantage of this approach is its relatively high cost.

\section{Aquifers and Contaminant Plumes: Migration of hazardous waste in the subsurface}

Whether or not bioremediation might be considered depends on the nature of the contamination and the conditions of the contaminated site. When talking about

\section{7a. Aquifers}

Water that soaks into the ground is called groundwater. If a sufficient quantity of water enters the ground, it will continue percolating downward past the root zone and zone of evaporation until it encounters an impermeable layer. Once groundwater can no longer move down, it fills pores in the rock.

An aquifer is a layer of rock or soil that is saturated with water and through the conditions of contamination of soils and groundwater, it is useful to understand a few things about aquifers and contaminant plumes.

which water flows in a quantity that can be extracted by wells. Water in aquifers flows through pores and cracks in rock, and between particles of sand and soil. The layer of water-saturated rock in the aquifer is called the saturated zone, because the pores are filled mostly with water. The ground above the aquifer is called the vadose zone. 


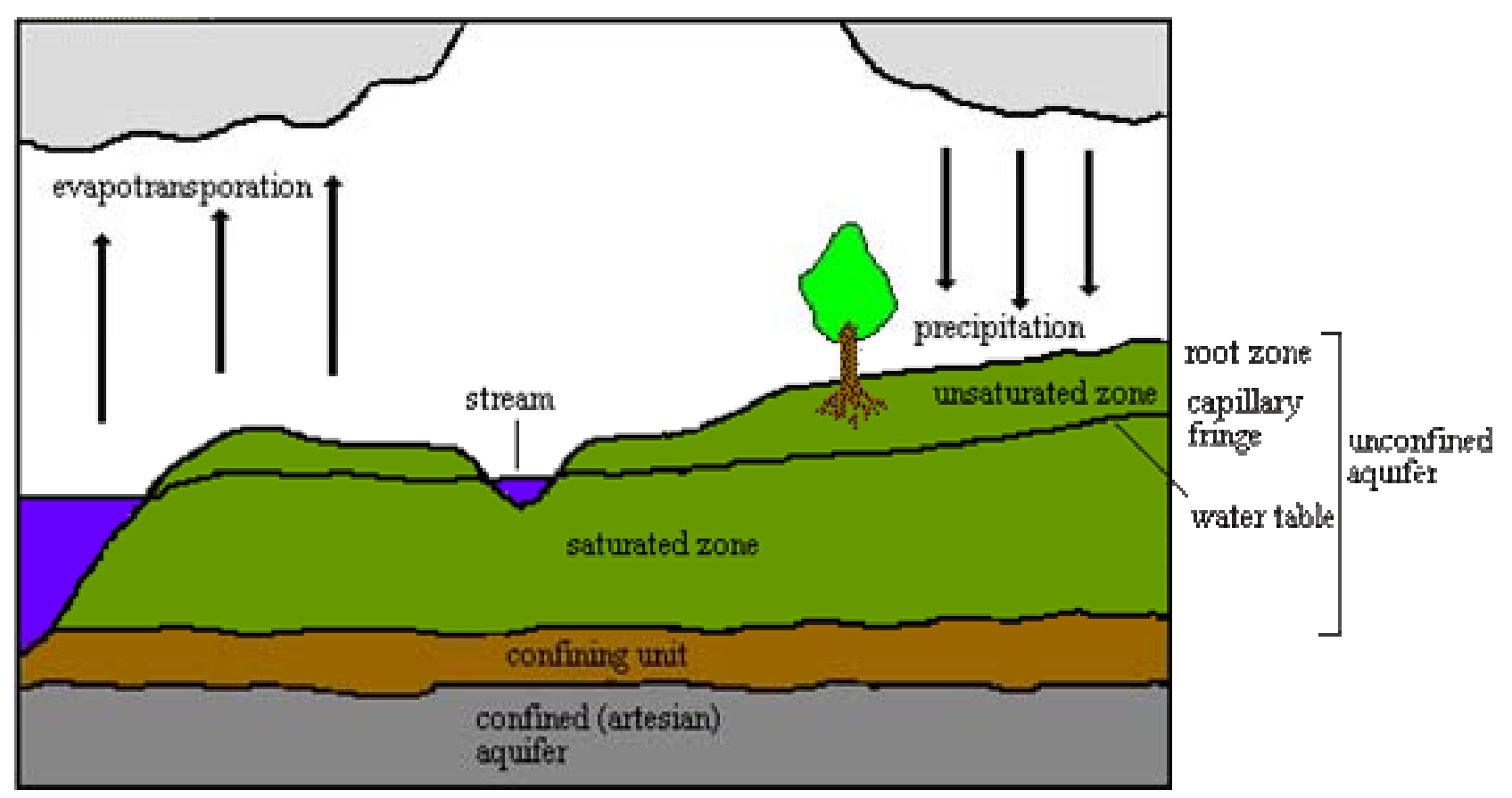

Figure 5: Illustration of an Aquifer

Groundwater has natural and artificial sources. Natural sources include rainfall and snowmelt that soak into the ground, and water that seeps into the ground beneath streams, rivers, and lakes. Artificial sources include water that soaks into the earth beneath irrigated fields, canals and wastewater drainfields, and wells designed to inject water into the ground. Industrial facilities with water systems can also contribute to groundwater, such as through leaking pipes and cooling ponds.

Groundwater enters, flows through, and leaves an aquifer in much the same manner as rainwater flows down slopes, fills lakes, and overflows riverbanks. In both cases the primary force acting on water flow is gravity. 
7b. Contaminant plumes

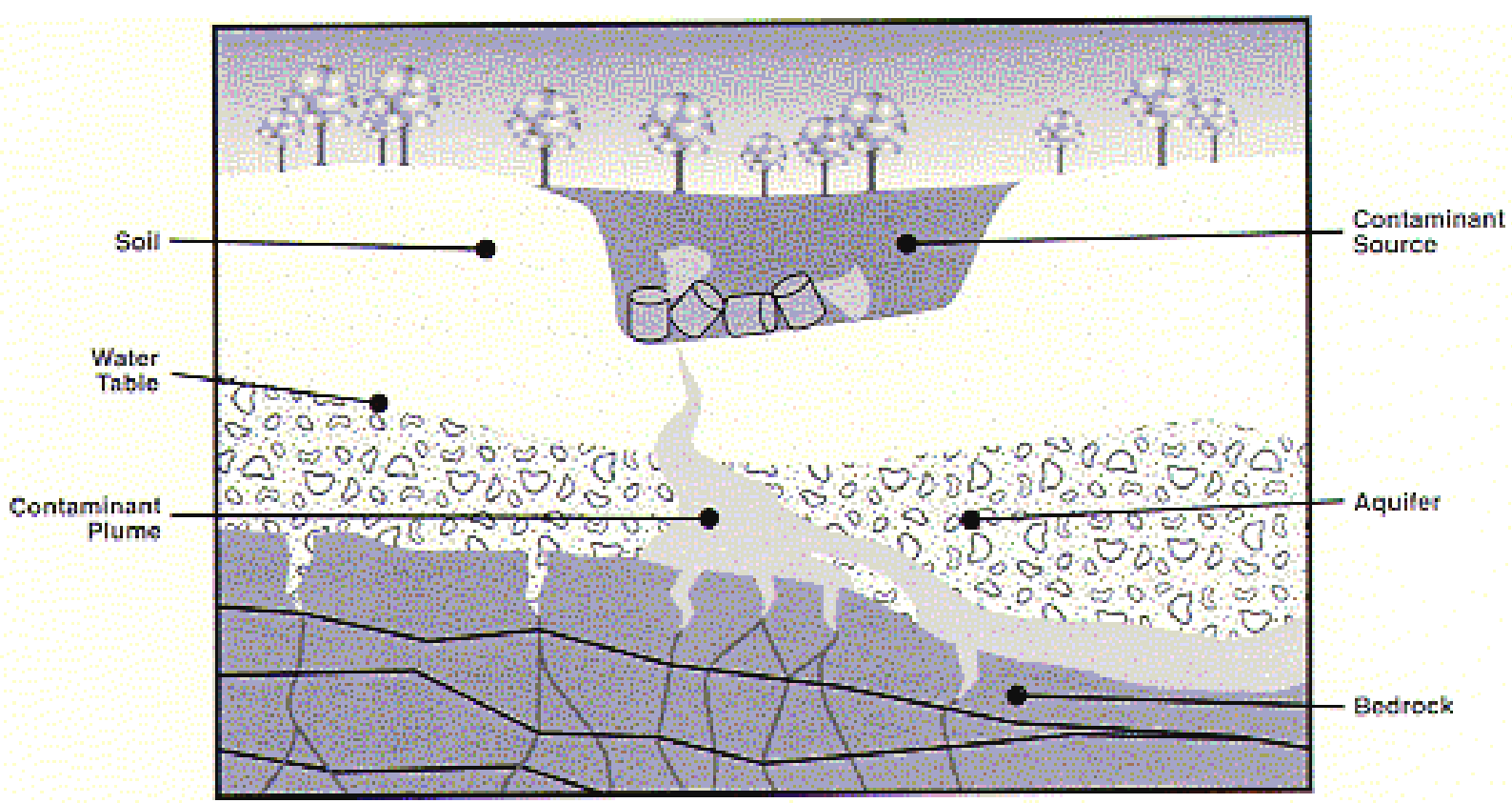

Figure 6: Schematic of Contaminant Plume

Contaminant plumes are zones of pollution extending downstream from sources of contamination. A source of contamination may be a single-point source such as a leaking tank or a nonpoint source such as contamination of water caused by use of agricultural chemicals or fallout from smokestacks. Sources of contamination are frequently spills, treatment lagoons, and disposal sites such as trenches, landfills, and underground storage tanks.

Once a contaminant is released into the environment, it can spread into the ground, groundwater, and surface water. The contaminant itself may be in a gas, liquid, or solid form, or a combination. Depending on the geology, how water moves through the site, and how well the contaminant dissolves in water, the plume may stay close to the source or be transported long distances by groundwater or rainwater. In some cases all of the contamination is caused by a single spill or leak. In others, the source of contamination may continue for decades - such as at an active waste disposal site - or when rainwater or other surface water percolates down through the zone of contamination.

In the groundwater, the shape of a plume will depend on the rate of migration, which is largely controlled by groundwater flow directions and velocity, the geologic setting, the physical and chemical characteristics of the contaminant, and the presence of a continuing source. 
8. Site Example: Bioremediation at INEEL

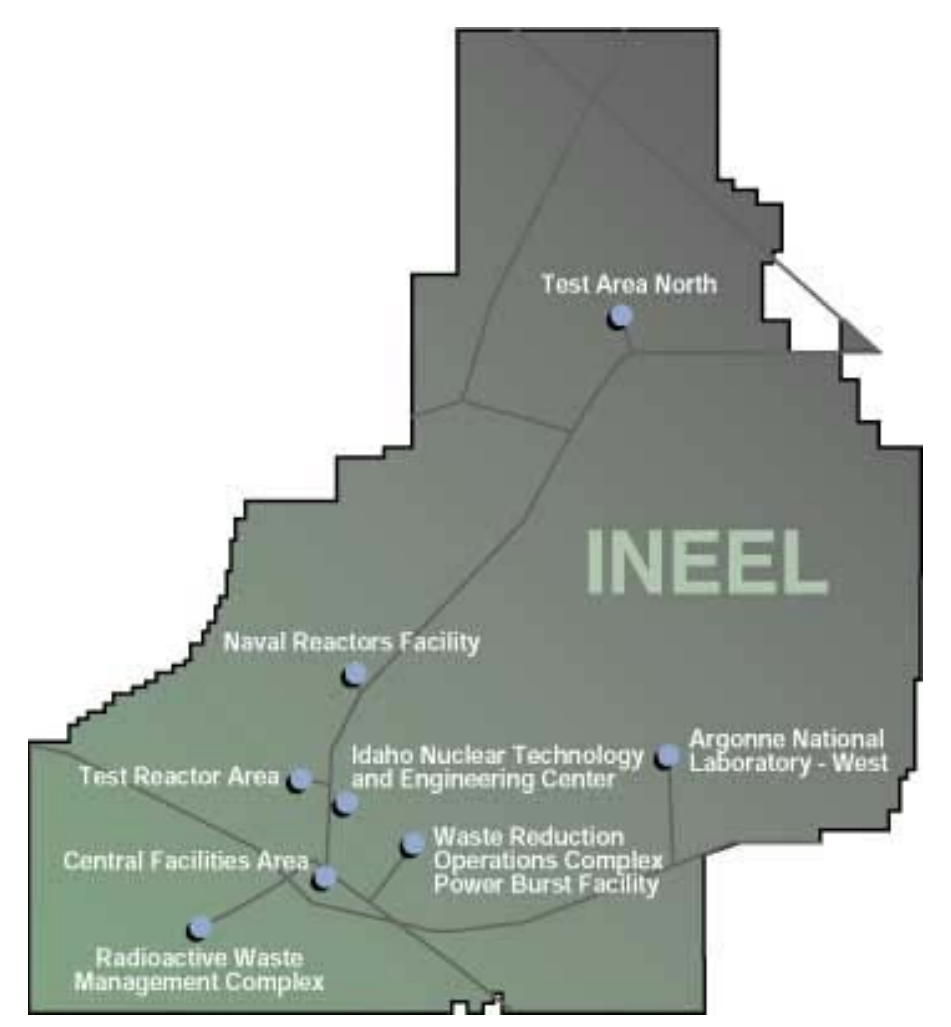

Figure 7: Map of INEEL Site

The Environmental Restoration Program at INEEL is responsible for remediating all of the INEEL's contaminated sites in accordance with federal laws. The INEEL was placed on the National Priorities List of hazardous waste sites (Superfund) in 1989, marking the beginning of INEEL's restoration program.

At present, groundwater leaving the INEEL's boundaries meets safe drinking water standards, and does not pose a risk to water users in neighboring communities and farms. To ensure that groundwater leaving the INEEL's boundaries continues to meet drinking water standards, cleanup work is underway to remove contaminants from the aquifer and to prevent other contaminants from entering the aquifer. In addition, the safety of human health and the environment at the INEEL requires the U.S. Department of Energy to clean up the aquifer beneath the INEEL to meet federal and state water quality standards. 
8a. The eastern Snake River Plain Aquifer

The eastern Snake River Plain Aquifer supplies about 2.5 billion gallons of groundwater every year for irrigation and industry, and is the sole source of drinking water for most of the people living on the plain. Most of the water in the eastern Snake River Plain Aquifer is clean and even requires no chlorination to be safe to drink. However, human activities on the eastern Snake River Plain have introduced contamination into the aquifer. One source of contamination is INEEL, which has contaminated portions of the aquifer at the INEEL with hazardous chemicals and radioactive substances.

The eastern portion of the Snake River Plain Aquifer begins near Ashton, Idaho, and flows southwestward to King Hill, Idaho (approximately 50 miles northwest of Twin Falls) in a broad crescent beneath the eastern Snake River Plain. Because the plain gently slopes from northeast to southwest, the aquifer likewise drains to the southwest, to springs along the Snake River. The aquifer contains an estimated 1 billion acre-feet of groundwater, about 600 times as much water as is held in the American Falls Reservoir (west of Pocatello). Only about one-fifth of the aquifer's capacity is considered economically available because groundwater at great depth is too expensive to pump or may contain too many minerals.

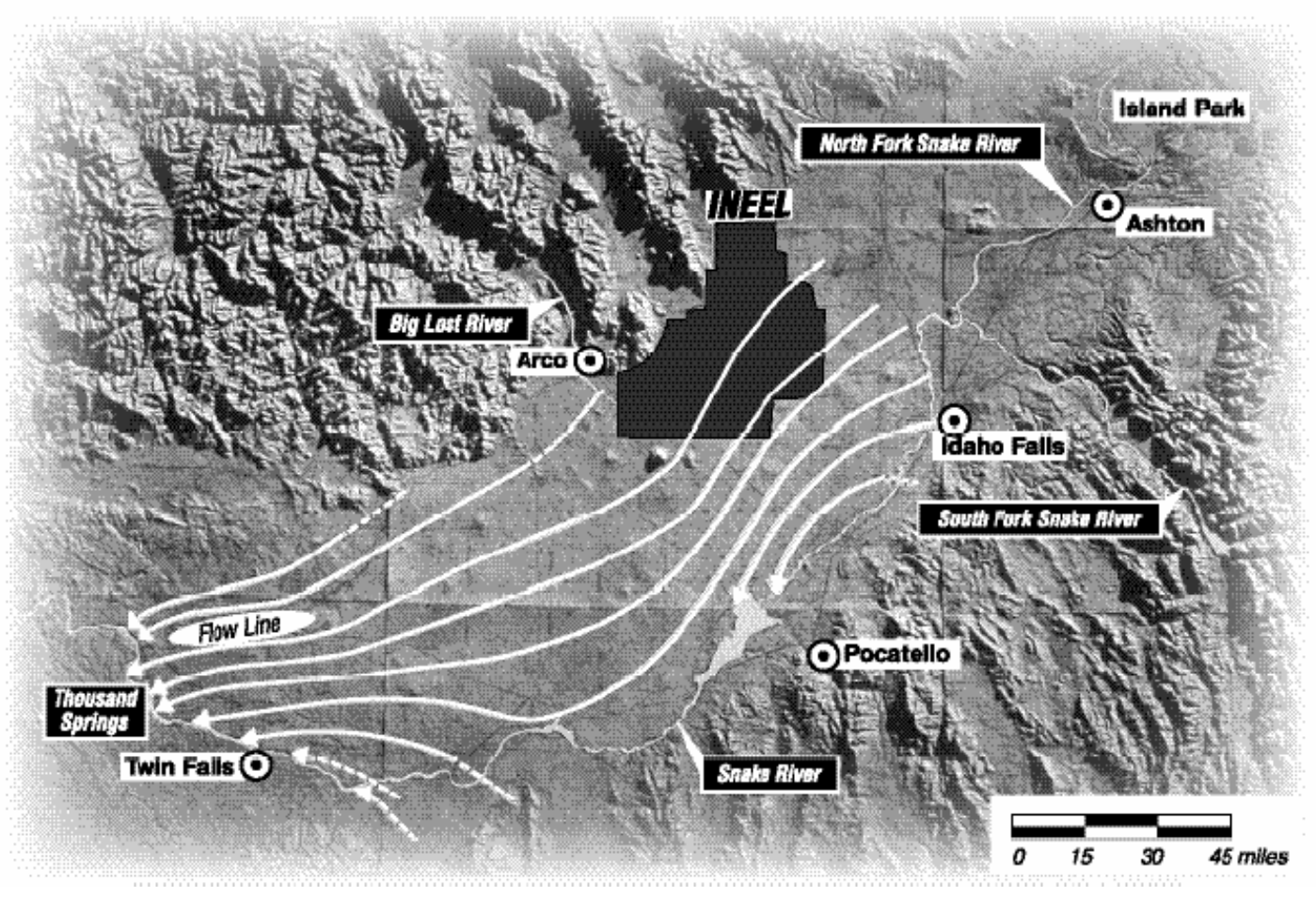

Figure 8: The Snake River Plain Aquifer 
The aquifer does not meet safe drinking water standards at five places, or facilities, within INEEL: Test Area North, the Test Reactor Area, the Idaho Nuclear Technology and Engineering Center (INTEC), the

Central Facilities Area, and the Radioactive Waste Management Complex. The aquifer at other INEEL facilities meets drinking water standards.

\section{8b. Plans for bioremediation at Test Area North}

Scientists have field tested bioremediation at Test Area North (TAN), one of the facilities at INEEL where the contamination exceeds drinking water standards. TAN was established in 1951 to support the Aircraft Nuclear Propulsion Program. Test Area North currently supports spent nuclear fuel inspection and storage, and the manufacture of armor for military vehicles.

The depth to the water table at Test Area North varies from 200 to 250 feet. The water table is closer to the surface at this area than at any other INEEL facility.

The contaminant in the aquifer at Test Area North that poses the greatest risk to human health is trichloroethylene, or TCE. TCE can cause liver damage and liver cancer at certain levels of exposure. While TCE breaks down rapidly in the atmosphere, it breaks down slowly in soil and groundwater. TCE will persist in the aquifer above drinking water standards for more than 100 years unless cleanup work reduces its concentration, particularly in the vicinity of high concentrations, or "hot spots." The areas where the contamination is at low concentrations is called the distal zone. The areas between the hot spots and the distal zones, where the contamination is at medium concentrations, is known as the medial zone.

Cesium-137, strontium-90, and tritium are present in low concentrations in the aquifer at Test Area North, and have relatively short half-lives. Their concentration in the aquifer is expected to naturally diminish to drinking water standards within 100 years.

Several methods have been used to remove the contamination at Test Area North, including pump-and-treat methods. However, pump-and-treat was not effective in reducing contaminant levels in the aquifer to drinking water standards because of unexpectedly high concentrations of contaminants in the groundwater and limitations of the treatment system. Alternative cleanup technologies have been evaluated for use at TAN.

After several years of field testing bioremediation at INEEL, three technologies have been selected for use for aquifer cleanup at TAN: accelerated in situ bioremediation at the source areas 
or hot spots, pump-and-treat at the medial zones, and intrinsic in situ bioremediation at the distal zones.

Field evaluation of accelerated bioremediation for hot spot cleanup began in November 1998, using lactate (a byproduct of fermented sugars commonly used in the medical and pharmaceutical industries) as the artificially-provided nutrient. INEEL scientists chose lactate because it is a good food for bacteria, inexpensive, non-hazardous to the environment, and highly soluble. Scientists expect this portion of the aquifer to be remediated within 15 years, up to twice as fast and for nearly \$23 million less than the originally selected technology of pumpand-treat.
Pump-and-treat technology, which began several years ago, will continue to treat the contaminated water in the medial zone.

Natural attenuation (or intrinsic in situ bioremediation) has also been field tested, and natural attenuation was selected as the preferred treatment alternative for the distal zones at TAN. Natural attenuation is expected to be effective within 100 years at Test Area North in the distal portion of the TCE plume, where concentrations are less than at the hot spots or the medial zones. Monitoring will be conducted to ensure the effectiveness of the natural attenuation in the distal zones.

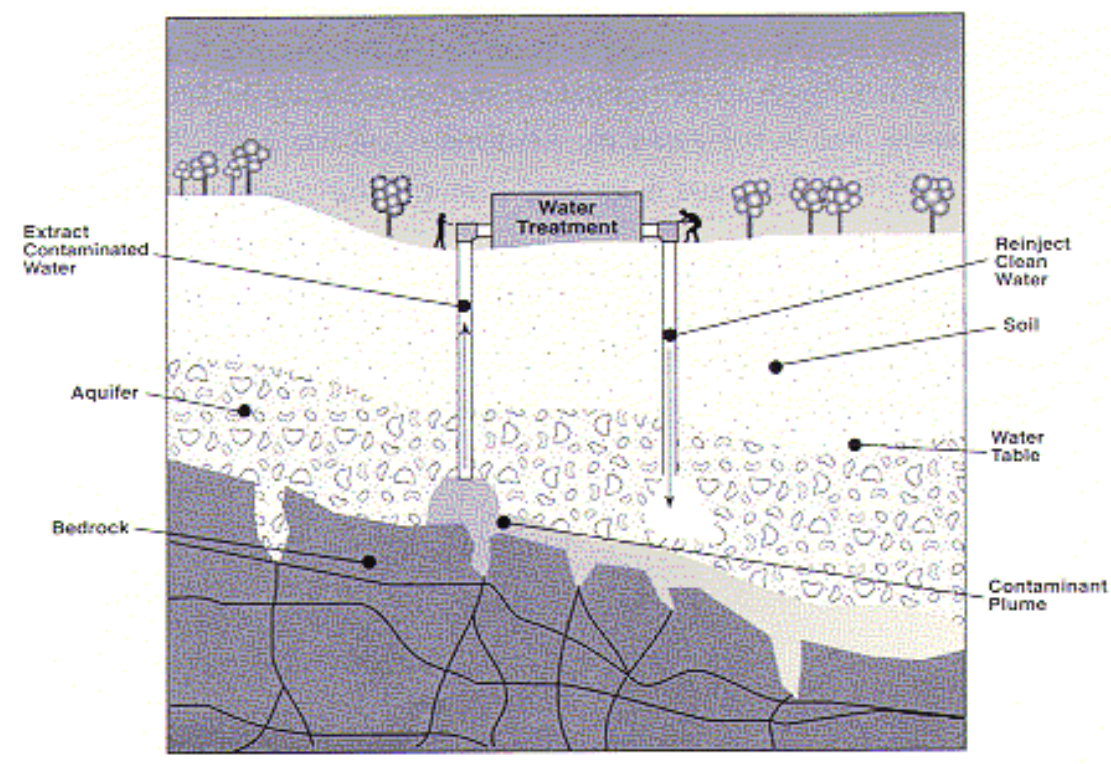

Figure 9: Pump and Treat Clean Up Technologies

8c. Comprehensive aquifer cleanup 
The eastern Snake River Plain Aquifer does not start and stop at the borders of each INEEL facility, just as it does not start and stop at the INEEL's borders. Aquifer contamination that originated at some INEEL facilities has spread A separate comprehensive investigation into aquifer and groundwater contamination for the entire INEEL began in 1999, more than two years ahead of schedule. Completion is scheduled for 2004. The investigation

\section{Summary of Cleanup Approaches}

This paper describes a variety of approaches to hazardous waste cleanup. These approaches and some of their beneath other INEEL facilities, and contaminant plumes have merged. Though aquifer contamination may be within acceptable limits at individual facilities, all aquifer contamination must be examined for cumulative effects. will examine the cumulative effects of INEEL activities and contamination of the aquifer, including the cumulative effects of long-lived radionuclide contamination. characteristics are summarized in the Figure 10 below.

\begin{tabular}{|c|c|c|c|c|c|}
\hline $\begin{array}{l}\text { Cleanup } \\
\text { Approach }\end{array}$ & $\begin{array}{l}\text { Cost } \\
\text { Effective }\end{array}$ & $\begin{array}{l}\text { Limits } \\
\text { Exposure }\end{array}$ & $\begin{array}{l}\text { Treats } \\
\text { Dispersed } \\
\text { Contamination }\end{array}$ & $\begin{array}{l}\text { Treats Low } \\
\text { Concentrations }\end{array}$ & $\begin{array}{l}\text { Difficult to } \\
\text { Control/Contain }\end{array}$ \\
\hline Dig and Haul & & $\mathrm{X}$ & & & \\
\hline Incineration & & $\bar{X}$ & & $\mathrm{X}$ & \\
\hline \multicolumn{6}{|l|}{$\begin{array}{l}\text { Chemical } \\
\text { Treatment } \\
\end{array}$} \\
\hline \multicolumn{6}{|l|}{ Pump and Treat } \\
\hline $\begin{array}{l}\text { Barrier/Filter } \\
\end{array}$ & $\overline{\mathrm{E}}$ & & & & \\
\hline \multicolumn{6}{|l|}{ Bioremediation } \\
\hline $\begin{array}{c}\text { Accelerated } \\
\text { bioremediation }\end{array}$ & & & $\bar{X}$ & 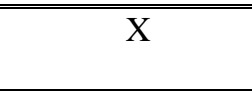 & \\
\hline $\begin{array}{l}\text { Intrinsic } \\
\text { bioremediation }\end{array}$ & $\bar{X}$ & & $\mathrm{X}$ & $\bar{X}$ & $\bar{X}$ \\
\hline $\begin{array}{l}\text { Phyto- } \\
\text { remediation }\end{array}$ & $\mathrm{X}$ & & $\mathrm{X}$ & $\mathrm{X}$ & $\mathrm{X}$ \\
\hline Landfarming & & $\bar{X}$ & & $\bar{X}$ & \\
\hline Bioslurry & & $\mathrm{X}$ & & $\mathrm{X}$ & \\
\hline Soil washing & & $\bar{X}$ & & & \\
\hline
\end{tabular}

Figure 10: Summary of Cleanup Approaches 


\section{Glossary}

Accelerated Bioremediation: Remediation that occurs at a faster pace than under normal conditions, usually achieved by the addition of electron donors, electron acceptors, nutrients or specialized microbes.

Acre-feet: A volume of water. One acre-foot of water-equivalent to 325,850 gallonscan irrigate an acre of alfalfa in the arid west for ten days during the summer.

Aerobic: Living, active, or occurring only in the presence of oxygen.

Anaerobic: Living, active, or occurring in the absence of oxygen.

Aquifer: A layer of water-saturated rock or soil through which water flows in a quantity useful to people.

Bioaugmentation: The addition of microorganisms to the environment.

Biodegradation: The breakdown of organic materials into simpler components by microorganisms.

Bioremediation: The use of microorganisms to degrade or transform hazardous organic contaminants or to transform hazardous inorganic contaminants to environmentally safe levels.

Biostimulation: Addition of nutrients, oxygen, or other "food sources" so as to increase microbial activity and biodegradation.

Cometabolism: Biodegradation of a substance by an organism that uses some other chemical for growth and energy.

Contaminant: Harmful or hazardous matter in the environment.

Contaminant Plume: A three-dimensional area of groundwater contamination.

Drinking Water Standards: The standards, also known as maximum contamination levels (MCLs), that establish the maximum permissible levels of contaminants in water delivered to any user of a public water system. The U.S. Environmental Protection Agency (EPA) has the authority to control these standards to protect the nation's drinking water. Because groundwater and surface water are often used in the same public water systems, regulatory agencies use MCLs to define contaminant levels for groundwater.

Electron Acceptor: A small inorganic or organic chemical that is reduced in a metabolic oxidation-reduction reaction. 
Electron Donor: A small inorganic or organic chemical that is oxidized in a metabolic oxidation-reduction reaction.

Ex situ: In a position or location other than the natural or original one. This usually refers to above-ground remediation, where the sediment or water has been extracted from the ground.

Genetic Engineering: The use of in vitro techniques in the isolation, manipulation, recombination, and expression of DNA, which includes reintroduction of the affected genes into cells of the same or different species.

Groundwater: Water found beneath the Earth's surface that fills pores between materials, such as sand, soil, or gravel; supplies wells and springs.

Half-Life: The time required for half of the atoms of a radioactive substance to disintegrate.

In situ: In the original position or place.

Inorganic Chemicals: Chemicals that do not contain carbon, which is usually associated with life processes; for example, metals are inorganic.

Intrinsic Bioremediation: Degradation or transformation of contaminants that consists of the naturally occurring microbial populations and naturally occurring chemical, biological, and geological conditions. Also known as natural attenuation, bioattenuation, or passive bioremediation.

Landfarming: A type of ex situ bioremediation that consists of mixing waste with surface soil over a tract of land.

Microbe or Microorganism: Any organism of microscopic or ultramicroscopic size; in the context of bioremediation, the microbes of interest typically are bacteria.

Organic Chemical: A chemical that contains carbon and hydrogen, elements usually associated with life processes.

Phytoremediation: A type of ex situ bioremediation consisting of the use of plants to degrade or transform contaminants.

Pump-and-treat: A cleanup technology in which groundwater is removed, treated, and then returned to the ground.

Radioactivity: Spontaneous emission by radionuclides of energetic particles through the disintegration of their atomic nuclei; the rays emitted. 
Radionuclide/Radioisotope: A type of element that is unstable; it tries to stabilize itself by giving off radioactive particles. This process is called "spontaneous decay."

Sediment: Material in suspension in water or deposited from suspension or precipitation.

Soil Washing: Remediation process by which soil is screened and large rocks and gravels are removed from clays, silts, and sands. The large rocks and gravels typically do not contain significant concentrations of chemicals of concern and are easily disposed of.

Slurry Bioreactor: Stirred tank in which a watery mixture of insoluble material is degraded or transformed in an aerobic environment (an environment in which air is present). 


\section{References}

All of the information above was adapted from the following publications:

a. McCullough, J., Hazen, T.C., Benson, S.M., Betting, F.B., \& Palmisano, A.C. (1999). Bioremediation of Metals and Radionuclides: What it is and How it Works. The Natural and Accelerated Bioremediation Research Program, Office of Biological and Environmental Research, Office of Science, U.S. Department of Energy (1999). Available at http://www.lbl.gov/NABIR/index.html

b. Accelerated In situ Bioremediation (ISB) (2001). Batelle PNWD Fact Sheet. Available at http://bioprocess.pnl.gov/isb_defn.htm

c. Basics of In situ Bioremediation (2002). A Batelle PNWD Fact Sheet. Available at http://bioprocess.pnl.gov/isb_defn.htm

d. Natural Attenuation (2001). A Batelle PNWD Fact Sheet. Available at http://bioprocess.pnl.gov/natural.htm

e. A Citizen’s Guide to Bioremediation (2001). Environmental Protection Agency. EPA publication no. 542-F-01-001. Available at http://www.epa.gov/tio/download/citizens/bioremediation.pdf

f. A Citizen's Guide to Monitored Natural Attenuation (2001). Environmental Protection Agency. EPA publication no. 542-F-01-004. Available at http://www.epa.gov/tio/download/citizens/mna.pdf

g. The Aquifer and the INEEL (2002). An INEEL Fact Sheet. Available at http://www.inel.gov/publicdocuments/factsheet/gwfsheet.pdf

h. Groundwater at the INEEL (2000). An INEEL Environmental Restoration Program Fact Sheet. Available at http://www.inel.gov/publicdocuments/factsheet/0201gwfsheet.pdf

i. Superfund for Students and Teachers: Common Cleanup Methods (1999). Environmental Protection Agency. Available at http://www.epa.gov/superfund/students/clas_act/haz-ed/ff_08.htm 


\section{Appendix C \\ Bioremediation Questions and Concerns Identified by Advisory Committee Members}

The contamination

- Metals

- Radioactive materials

- Mixed contaminants

- Some contaminants can be destroyed, others can't be destroyed

- How deep is the contamination?

- What are the effects of the contamination on human health?

- What are the effects of the contamination on the environment?

- What are the effects of the contamination on the ecosystem?

The technology

- Bioaugmentation is the introduction of a natural bug

- Attenuation may be intrinsic (natural) or engineered (enhanced)

- The technology will destroy organics (a good thing)

- The technology will not destroy metals (not a good thing)

- How deep will the bugs go?

- Can you contain the radioactive materials long enough until they decay?

- Identify other sites in Idaho where the technology has been used.

- Is it harmful?

- What do we know about the microbes?

- What happens after you walk away?

- How does it work?

- What are the by-products?

- Will the added chemicals cause any problems?

- How do you know it works?

- What are the pros and cons?

- What are the costs?

-

What are the risks of the technology?

- What could go wrong?

- Worker safety

- Will the bioremediation mobilize bad things, like arsenic?

- For the immobilization approach, what might change the situation, i.e. cause problems? Earthquake? Flood? Farming activities?

- What are all the things that could have an impact on bioremediation/immobilization?

- What about farming? E.g. Plant uptake?

- Identify any low-probability/high risk (negative, worst-case) scenarios

- What are the effects on endangered species on the surface, for example sage brush (sage grouse?)?

- What are the effects on other plants and animals, surface \& subsurface?

- What kinds of quantities of microbes, added substances, or products will result from the process (e.g. tanker car-loads of lactate)?

- How might native (microbes, other species) be affected?

- How will it affect the ecosystem? 
Limitations of the technology

- What are the limitations of using bioremediation?

- Are there climate considerations?

- Different consideration for soil v. water, for example?

\section{Alternatives}

- Why not dig it up?

- Is there something that works faster?

- Can we mine it for something valuable?

\section{Socio-political-cultural concerns}

- If you just immobilize, will the public have concerns?

- Political aspects; e.g. TAN, areas of contamination

- Is there enough public trust of DOE to accept any long-term clean-up strategy?

Miscellaneous

- Focus on Idaho \& INEEL 


\section{Appendix D: Working Script for Workshop Session \\ WORKING SCRIPT \\ FRIDAY - NOON - 8:30 PM}

On Tables:

- Ice water and glasses

- Pencil and paper

- Name plates

- Notebooks

\section{Need in Room:}

- 3 easels

- 3 sets of chart packs with pens

- 15 copies of agenda for Friday + Saturday (3-hole punched)

- Overhead projector

- Computer projector + laptop connection
- "yellow cards"

- Extra copies of "glossary" from remediation paper

- Agenda rewritten for wall

- Chart pack prep for "key concepts” for bioremediation

- Large cards for report outline

- Blue tack

- Notetaker

$\rightarrow=$ Action Item

\begin{tabular}{ll}
\hline Time & Topic \\
\hline Noon & Lunch Served -Mini Cassia Board Room \\
& $\begin{array}{l}\text { Denise - Small welcome - introduce JAG } \\
\text { (Exercise - next-to-you “buddy" introductions) } \\
\text { Introduc tions - JAG lead }\end{array}$ \\
- Use group process \\
- Review agenda (up on wall) \\
1:00 pm
\end{tabular}


$2: 15 \mathrm{pm}$

2:45 pm

3:00 pm

$3: 30 \mathrm{pm}$

4:00 pm

$5: 00 \mathrm{pm}$

\section{Group mission and charter}

...Janet Gillaspie

...Small Group exercise - (15 minutes) break into 3 groups of 5

Group process - need 3 things - 1. recorder, 2. discussion leader, 3. Timekeeper...

1. Inventory "common items" for each member

2. Review and suggest revisions to mission/charter

Report back to entire group - (15 minutes - 5 minutes for inventory; 10 minutes for charter review)

\section{$\rightarrow$ Disc ussion and consensus on charter from group}

B R E A K - food available

(puzzle for return...)

(Take questions as you go - - use yellow cards...)

\section{Basics of Bioremediation Science}

...Ken Williamson

\section{Questions and Disc ussion}

...All

\section{Inventory of Bioremediation Science} ...All

Put information in our own words - we own it. Discussion can highlight areas of uncertainty.

Goal - summarize IN OWN WORDS what bioremediation is all about "Grocery store aisle" summary

- Break into 3 groups of 5 (use same groups for day)

Group process - need 3 things - 1. recorder, 2. discussion leader, 3. Timekeeper...

- Small group exercise

- Write key concepts that summarize what you know about bioremediation - - just the key concepts - "grocery store aisle" type summary

- 4, 5, 6 key concepts

- Show some examples (prep chart pack)

Group Consensus on Bioremediation Science ...All

-presentations by groups

$\rightarrow$ pull into one section 
$\rightarrow$ During dinner - write a single paragraph that pulls all the

technology science statements into a single set of statements

6:00 pm Dinner-Courtyard

(no formal activities)

(promote informal discussion)

7:30 pm Report outline disc ussion

-Start exercise (all together) to determine elements of the report -

1. Inventory on chart pack chapter list (introduction, executive summary, etc.). Rewrite chapter list on separate pieces of chart pack.

2. Write text elements (topics) on large cards and use bluetack to post in order - move cards around as necessary.

3. $\rightarrow$ This report outline will need to be typed and copied for review and comment on Saturday.

-Watch group energy - if lagging - move to +/- exercise and end early.

8:10 pm Review of Day

- do +/- exercise

\section{Ask group for suggested changes for tomomow???}

Breakfast served at 8:00 am - start in Mini-Cassia Room at 8:30 am

$8: 30 \mathrm{pm}$

Adjoum

Need for Saturday:

- Make adjustments based on +/- exercise

- Write up and copy technology "statements" to single chart pack and copies

- Make adjustments to charter and leave posted

- Translate "rules of the road" to simple statements and print on "bright sticky" to put on back on name plates

- Type up and copy outline of report - Use "outline” function in Word to start building document

- Find outdoor activity for Saturday afternoon (horseshoes??) 
Appendix E

\section{List of Experts Participating in the Consensus Workshop}

1. Basics of Bioremediation Science

Ken Williamson, Oregon State University

2. INEEL Site: Historical Summary

Jan Brown, INEEL

3. Geology and Hydrogeology of INEEL Site

Dan Ackerman, US Geological Survey

4. Bioremediation Projects Underway at INEEL

Lance Peterson, North Wind Environmental

5. Policy Options for Long Term Stewardship

Kathleen Trever, Idaho DEQ

6. Bioremediation of Radioactive Contaminants and Metals

Dr. Jonathan Istok, Oregon State University

7. Public Health and Risk Assessment Approaches

Bob Nitschke, INEEL

8. Cleanup Techniques - A Comparison

Ken Williamson, Oregon State University

9. A State's Option for Securing Long Term Stewardship

Laird Noh, Idaho Senator 
Appendix F: Consensus Report

\section{Bioremediation as a Remediation Technology} A Consensus Report From A Citizen Panel To The Department Of Energy

September 2002 


\section{Dear Reader,}

We the citizen panel, individually and collectively, have been given a unique and challenging opportunity. We were involved in a process to inform decision-makers about citizens' views about and attitudes toward new technologies in the hope that citizens become regarded as equal partners in the decision-making process. We have leamed, made decisions, and come to understand the uses and the risks of bioremediation; we have written a consensus report based on our experience.

There are many points of concem related to bioremediation and we have summarized them into six major areas in our report: bioremediation technology, health and risk assessment, comparing bioremediation to other technologies, education and outreach, responsibility and lia bility, and long-term stewardship.

Overall, we would highlight our issues and concems about the use of bioremediation as a remediation tool according to the following points:

\section{Selection of Treatment}

Our exploration of remediation treatments led us to an understanding of bioremediation as an effective approach for INEEL and other sites. Bioremediation offers a solution on several fronts: it costs less, treats contamination in the ground, and avoids transportation and storage concems. Bioremediation is a method that can be used on a variety of contaminants including radionuclides and metals.

\section{Health and Risk Assessment}

Underlying much of our disc ussion were issues of health. Risk assessment is an important key to understanding and approaching remediation issues. Important health risks associated with the application of bioremediation for metals and radionuclides include the concentration of contaminants and exposure in and around the site to both workers and the public.

\section{Education and Outreach}

We have talked, argued, disc ussed, and listened to the ideas of others to reach consensus. This process could provide a template for INEEL to use in its public outreach programs.

\section{Long-term Stewardship}

These issues require continuity of political leadership and commitment to remediation goals. This in tum requires an actively engaged public.

\section{Research Issues}

Based on the information we received from scientists and other informed speakers we came to realize there are several research issues that need to be resolved. Scientists know little about large-scale applications of bioremediation and need more information about subsurface characteristics depending on the site and conditions.

As citizen panel members we hope we are a reflection of the concems of the citizens of Idaho. Serving was a privilege and an honor. It is important to us that our work be ca refully considered. 
- Signature Page Here - 


\section{TABLE OF CONTENTS}

INTRODUCTION ............................................................................................ 5

BIOREMEDIATION SUMMARY ................................................................ 6

Background Information

A Summary of Knowledge about Bioremediation

Acquired by the Panel

PANEL PROCESS

8

Criteria for Selecting Panel Members

How We Worked with Each Other and What We Did

Evaluation: What Worked and What Didn't

Recommendations

ISSUES, CONCERNS, AND RECOMMENDATIONS

Bioremediation Technology

Health and Risk Assessment

Comparing Bioremediation to OtherTechnologies

Education and Outreach

Responsibility and Liability

Long Term Stewardship

CONCLUSIONS

APPENDICES

A: Glossary of Tems and Acronyms

B: Rec nuitment Ad

C: Panel Members and Staff

D: Citizen Panel Charter

E: Press Release

F: Early Questions and Concems

G: Technical and Scientific Presenters

$H:$ Presentations 


\section{INTRODUCTION}

We are ten citizens from Southem Idaho who were selected to take part in a citizen panel consensus workshop for thinking about bioremediation. Our tasks were to leam about bioremediation and to write a report describing what we leamed, explaining our understanding of bioremediation as a cleanup method, reporting our concems and issues and making recommendations about the use of bioremediation. This is a research project conducted by Oregon State University and funded by the U.S. Department of Energy, which is the primary audience for the report, along with other interested citizens or professional parties.

The research is three-fold: to identify potential public issues and concems related to bioremediation, to make recommendations that could address such issues and concems, and to understand how the consensus workshop process may help provide the DOE with a public perspective.

We met for three 2- or 3-day sessions in Burley, Idaho during the months of J uly, August, and September 2002. The consensus report was completed during the final 3-day session.

This report contains information about how the process worked with the citizen panel members, the invited speakers, and the project staff. The report presents our issues, concems, and recommendations about six general topics on bioremediation including bioremediation technology, health and risk assessment, companing bioremediation to other technologies, education and outreach, responsibility and liability, and long-term stewardship. Finally, we present our conclusions.

The initial sections of the report focus on bioremediation as a technology. As we progressed in our leaming about bioremediation, the institutional aspects of responsibility and liability, and long-term stewardship emerged. These issues would equally apply to other remediation technologies.

Appendices are provided for additional information. Additional information is also available at the project Web site: http://www.cwest.orst.edu/nabir/index.htm. 


\section{BIOREMEDIATION SUMMARY}

\section{Bac kground Information}

Bioremediation is a treatment for the cleanup of hazardous waste that uses bacteria to break down or change contaminants into less toxic or nontoxic substances. Microorganisms* that live in soil and groundwater can consume certain hamful contaminants. One kind of bioremediation, used for organic chemic als such as oils and gasoline, involves mic robes using contaminants as a "food source;" in this way, the contaminants are changed into water and harmless gases such as carbon dioxide. Bioremediation has been successfully used on organic chemicals, like fuels and solvents, which contain primarily carbon and hydrogen atoms. Scientists a re now looking at the possibility of using bioremediation on inorganic chemicals like radionuclides (radioactive chemicals) and metals.

A significant portion of the contamination at Department of Energy (DOE) sites consists of radionuclides and metals and the DOE is especially interested in whether or not bioremediation can be used to remediate such contaminants. Radioactive and metallic contaminants at DOE sites include cesium, chromium, lead, mercury, plutonium, uranium, strontium, and technetium. All are metallic elements with varying high levels of toxic ity.

The bioremediation process described above, where microbes degrade oils or other organic chemicals and change them to water and carbon dioxide, doesn't occur for metals and radionuclides. Metals and radionuclides cannot be biodegraded. However, microorganisms can interact with radionuclides and metals and transform them from one chemical form to another. This transfomation may result in increased mobility of the contaminant and allow it be more easily flushed from the site. In other cases, the opposite may occur and the contaminant will be immobilized in the ground, thus reducing the risk to humans and the environment. Both kinds of tra nsformations present opportunities for bioremediation of metals and radionuclides - either to keep them in place or to speed up their removal.

\section{A Summary of Knowledge about Bioremediation Acquired by the Panel}

- Bioremediation is a cleanup technique that either transforms harmful chemicals or alters the mobility of contaminants at a polluted site.

- Bioremediation is a natural process that uses bacteria, nutrients and water in whatevercombination necessary to change these materials to less haza rdous forms through degra dation or transformation.

- Bacteria are already present in the environment and bioremediation may speed the process of breakdown or immobilization.

\footnotetext{
* Definitions for italic ized words are included in Appendix A
} 
- The contaminant of concem tells you what bioremediation process to use:

- Transformation: Add chemicals to act as electron donors, electron acceptors or both.

- Mobility: Add chemicals to change the environment from oxidative to reductive.

- Different technologies are used to deliver the needed ingredients depending on where the contamination is located. The contaminant could be diluted in the groundwater, air, or soil. The contamination could be a pocket of pure chemical.

- Other important ideas include:

- Conta minants occur through spills and/or improper disposal.

- Cost effectiveness and safety are important, though the public would like all conta minants to be eliminated or contained.

- You can control and/or speed up the reaction based on what you add.

- The field experience of using bioremediation on radioactive contaminants is limited-it has only been conducted on a very small scale.

- This technology has been proven to be effective in some areas, and is promising in others.

- Examples where bioremediation has been used:

- oil spills in Alaska

- limited or contained petroleum spills

- composting

- chlorinated solvent cleanup. 


\section{PANEL PROCESS}

The consensus workshop process includes getting a cross-section of people in the affected area to serve on the panel. In this case, a good demographic mix was achieved. We believe the panel represented the range of the ideas and backgrounds of Southem Idaho citizens. This panel was an experiment to see if bringing people together in a concentrated effort in this workshop could make a difference in understanding this issue.

\section{Criteria for Selecting Panel Members ${ }^{2}$}

Recruitment ads for panel members were placed in four southem Idaho newspapers (Boise Idaho Statesman, Idaho Falls Post Register, Twin Falls Time News, and the Pocatello Idaho State J oumal). Criteria for participation included ability to attend all three workshop sessions, at least 18 years old, and no expert knowledge of bioremediation. Applicants were asked to provide a brief, onepage letter describing themselves and why they would like to participate. The recruitment ad is attached as Appendix B.

Twenty-six individuals a pplied. A wide variety of criteria were then used to select the ten final panelists. The goal was to create a diverse panel of Idaho residents. The selection criteria included:
- Age
- Gender
- Ethnicity
- Residence
- Religion
- Years in Idaho
- Income
- Education
- Knowledge of INEEL
- Occupation
- Knowledge of bioremediation

Final panelists include five women and five men ranging in age from 21 to 70 . They live in many communities across southem Idaho. Panelists a re equally diverse in education and occupation, with many being long-time or native residents of Idaho. While most panelists know about the INEEL because it is such an important part of the economy, only one participant has ever worked at the lab. All participants had no prior knowledge about bioremediation. Panel members are listed in Appendix C.

\section{Meetings: How We Worked With Each Other and What We Did}

One of the first things we did as a panel was develop a "Charter" describing our purpose, the scope of our task, how we would work together, and our expected outcomes. This Charter was revised during the July 2002 workshop and then posted each time we met to remind us of our task. The Charter is attached to this report as Appendix D.

\footnotetext{
${ }^{2}$ This section was written and provided by the project directors.
} 


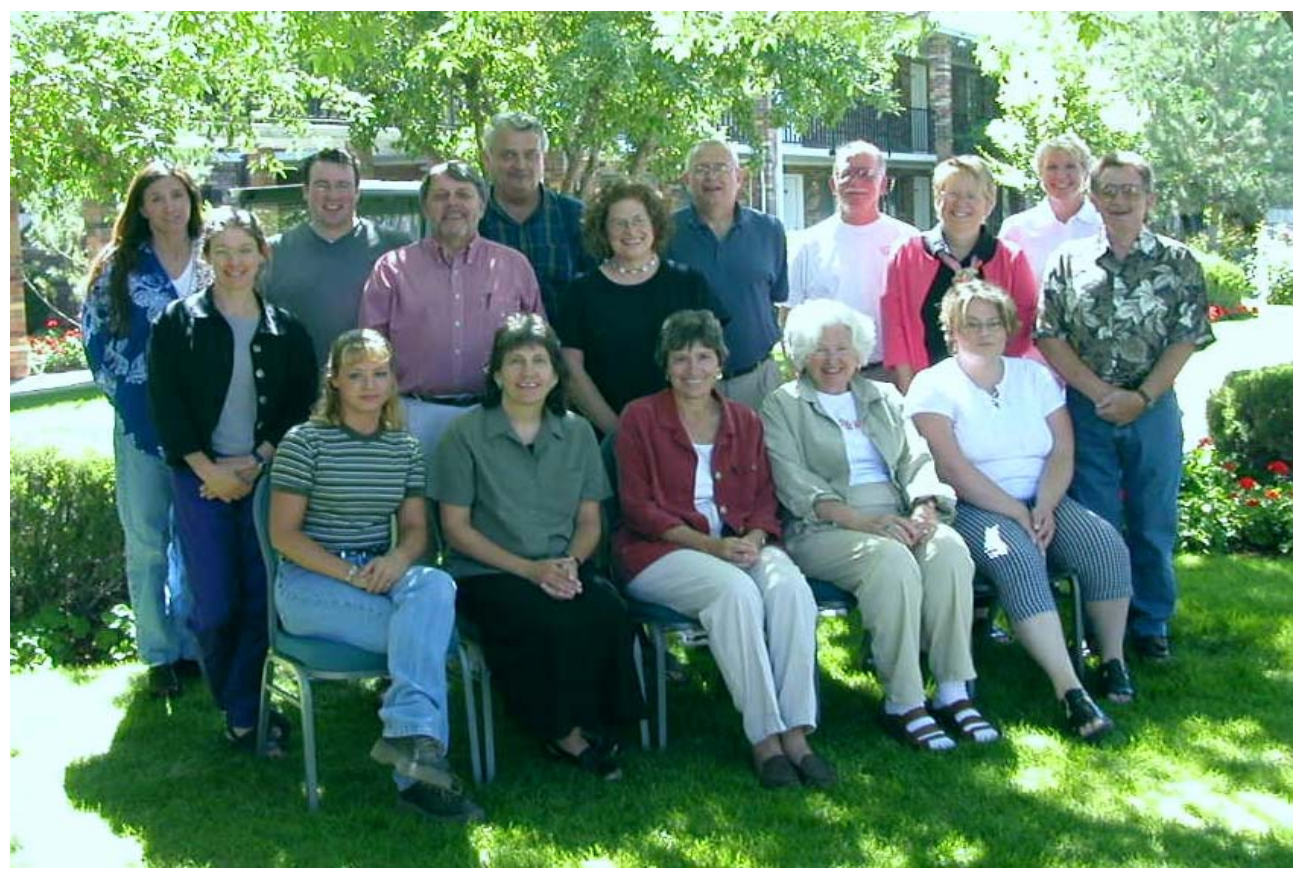

Sitting: Debi J ohnson, Stephanie Sa nford, J an Brown, Ka y Meriam, Sheri Thomson

Stand ing: J ulie Knopp, Dorothy Tib betts, Rob Smith, Tim Rhodes, Don Robinson, Fran Peterson, Ken Williamson, Biff Parks, Denise Lach, Janet Gillaspie, Dennis Lloyd

Key milestones in the panel process were to:

1. Inventory panel members' concems regarding bioremediation as an environmental remediation tec hnique.

2. Leam adequate scientific infomation about bioremediation of environmental contamination issues to be able to describe them for the report.

3. With the information from milestones \#1 and \#2, complete a list of technical questions that specific experts should address to the panel. The experts' qualific ations or other past work experience of interest to the panel should be included.

4. Reach consensus on questions, answers received, and recommendations regarding:

- Use of bioremediation techniques to treat legacy environmental pollution problems, and

- Use of a consensus citizen panel for citizen participation and input in to the remediation decision-making process.

5. Pull all the information into a single written report. Gain approval for the document from all panel members. Signify approval by signing the report. 
The Charter also included "rules of the road" or how we would operate during our meetings.

The panel reviewed a press release describing the bioremediation consensus workshop that was released to four southem Idaho papers (Boise Idaho Statesman, Idaho Falls Post Register, Twin Falls Time News, and the Pocatello Idaho State J oumal). The news release is included as Appendix E.

The panel has worked very well together and some of that is related to the facilitation and the friendly help we got from the project leaders. The atmosphere was very important to helping the panel work together. The workshop leaders allowed us to think for ourselves. The rules, materials, and workshop design helped the group work effectively.

We combined receiving information with the opportunity to discuss, digest, and restate the information in our own words. The written material provided to the panel was understandable and at the correct level of detail. At every meeting, we used large group information-gathering, small group discussion, and then an opportunity to write our ideas. The panel also interacted with the scientists and managers to expand our level of understanding about bioremediation and the cleanup at INEEL. This information and the resulting disc ussion have changed our perceptions about bioremediation and the remediation efforts at INEEL.

The panel met for three weekends over the Summer of 2002. We met at the same location in Burley, Idaho for all three sessions. Burley was a central meeting point for partic ipants.

The goal of the workshop was to write a consensus report. The task of writing the report was incomorated into the entire workshop, and along the way we had healthy experiences in reaching consensus. This may be because of the goalorientation toward finishing the report. In addition to these weighty and challenging activities, we also had fun together.

Attached in Appendix $F$ is the list of questions the panel initially identified as important to know. We used these questions to identify the type of presenters we wanted to hear from and the information we needed.

The initial list of questions demonstrates that we had many concems. New understanding quickly showed us that this shotgun approach needed refinement. As a result, we narrowed the scope of our inquiry down to essentials.

\section{Working with the Sc ientists and Managers}

The group disc ussed the types of scientists and managers we were interested in lea ming from. In general we were looking for people with the minimum qualific a tions of:

- Exc ellent scientist or expert in field

- Good communic ator 
- Broad points of view

- Expert with wide perspective

We thought we would like to hear from people with expertise in the following areas:

- Mic robiologist

- Geochemist

- Hydrologist

- Geologist

- Health effects/human health

- Monitoring expert

- Risk a na lyst

In addition, we identified several areas of expertise and/or affiliation that we were interested in hearing from including:

- An independent scientist-not in the govemment loop; no money at stake

- Some govemment scientists, e.g. EPA or DOE

- An opponent of bioremediation, or a proponent of a nother method

- A regulatory expert, could be

- Hanford focus,

- INEEL foc us, and/or

- clea nup activity expert

- Local or state elected officials

- Land management agency, such as

- US Forest Service

- Bureau of Land Management

Append ix $\mathrm{G}$ conta ins short biographic al statements of all technic al and scientific presenters. Appendix $\mathrm{H}$ contains a list of presentations and a web site address where some presentation materials are available.

\section{Evaluation: What Worked and What Didn't}

The group concluded that some aspects of the workshops worked well including:

- Professional facilitation was essential.

- Workshop was convened by a neutral, but professional and experienced organization.

- Project coordinators were leaming about bioremediation a long with the group.

- Combination of small and large group interactions got us to a level of understand ing very quic kly.

- Intense weekends helped concentrate our efforts. (Sundays off was good)

- Conversations were positive with respect for all partic ipants.

- Selected scientists and managers that could answer our questions.

- Facilitators and leaders helped to keep us on track. 
- Revisiting ground rules kept us paying attention to the way we interacted.

- Handouts provided information above and beyond what we leamed in workshop sessions.

- Comfortable venue.

Some aspects that could have been improved included:

- Most things that didn't work were along the lines of small creature comforts (e.g. room temperatures, food, etc.). These were taken care of by the project staff.

- Some speakers could have been more on-topic.

- Panel members could have benefited from a check-in right before the meeting to see if any additional information was needed.

- It would have helped to have the presenters' materials before the meeting for review.

\section{Recommendations}

- This kind of process works. Instead of DOE doing public relations (often perceived as deceptive by the public), the panel has become engaged in the process of leaming about remediation at DOE sites in a factual way. Instead of DOE telling people what they think the public should know, they should use the consensus workshop as a way of providing information and soliciting input.

- A successful workshop must have both impassioned, but impartial, facilitators and leaders.

- Make frequent use of consensus panels so more people can become involved with issues at sites.

- Provide practical and pragmatic information about a wide range of issues, including politics, risk assessment, technology, and communication with the public. This workshop strategy can provide citizens with information they can find no where else.

- Panels should never be patronized, regardless of what workshop sponsors think they know or don't know.

- Panel size is important; panelists need opportunities to share and come to consensus. Twenty may be the maximum number of panelists.

- It is suggested that pa nelists consider holding a mini-c onsensus workshop of their own with people they know and then come back together to share what they have lea med.

- DOE should take positive steps toward integrating consensus workshops in public involvement efforts. 
- DOE should pay attention to consensus workshop reports and consider them as substantive expressions of public concems.

- DOE should continue to leam about consensus workshops and other public involvement activities that genuinely engage the public.

- The DOE made a significant investment in educating this panel. With the new knowledge gained, the panelists could be utilitized to communicate in a creative way with the public. Capitalize on this investment by using these participants in a presentation process for the INEEL. 


\section{ISSUES, CONCERSS AND RECOMMENDATIONS}

\section{Bioremediation Tec hnology}

\section{Issues}

Based upon the information provided, we believe that bioremediation is an effective way of treating contaminants to lessen their negative effects. Bioremediation has the potential to lower the cost of remediation by orders of magnitude over altemative technologies. Govemmental agencies, and the public as taxpayers, are interested in cost effective cleanup technologies. Economical treatment methods should allow more sites to be cleaned up. In addition, bioremediation is something that uses natural processes in the ground and can be done without having to bring the toxic material above ground. We like the idea of being able to use the technology that is the least invasive and intrusive to take care of toxic waste.

\section{Concems Related to Bioremediation}

Clean up of sites needs to be effective and bioremediation should not be the technology of choice just because of cost. This is of special concem at DOE sites where the remediation process is driven by contractors.

Bioremediation concems include:

- Bioremediation appears to have been tested on only a limited number of sites, especially for the remediation of metals and radionuclides.

- Effectiveness of bioremediation in the vadose zone and at deep levels, where considerable conta mination at DOE sites exists, is unknown.

- The use of bioremediation where there are numerous contaminants in a particular site appears to be difficult and presents high uncertainty of effec tiveness.

- Some concem exists with the potential mutation of bacteria in the presence of radioactive wastes.

In addition, for certain toxic organic compounds, there is always a concem of creating "dangerous daughter" products with greater toxic ity.

Long-term clogging of aquifers appears to be a potential problem with all forms of bioremediation. The ability to recover from clogging is unknown.

Geology and site characterization are essential for the effective use of bioremediation. Because of the specific geology at a site, it is difficult to translate the success or failure of bioremediation from one site to another. For example, the geology in Idaho raises a question of how the success at INEEL can be applied to other sites.

For the bioremediation of metals, the metals may go back to a mobile state if bioremediation is not continuously maintained. This raises considerable issues 
related to long-term stewardship and whether bioremediation can be maintained with DOE's changing foci and politic al climate.

\section{Recommendations}

- A sound risk assessment is needed before we decide how to apply bioremediation.

- Bioremediation should only be used when there is a reasonable guarantee of success.

- Research should continue to be funded and expanded to larger demonstration projects.

\section{Health and Risk Assessment}

\section{Issues and concems}

As community members, our concems related to bioremediation as a remediation technology revolve around public and worker heath issues.

There a re major health risks associated with contamination at a site. Pathways of exposure to people include water, air, and agriculture (food grown in contaminated soils and water). Humans can be exposed to toxic substances by inhalation, ingestion, indirectly, and dermal contact. Cleanup technologies should be chosen that lower these risks to residents and workers. An accurate risk assessment can foc us cleanup efforts in a reas of highest human health risk.

Bioremediation appears to be a good technology because the contaminants remain underground, reducing the pathways for exposure. Also the risk of exposure to workers is reduced if bioremediation is used rather than technologies that require removing and transporting contaminants.

If bioremediation is used, there is a risk associated with the concentration of contaminants that occur duning bioremediation. If there is an exposure, the risks may be greater than prior to bioremediation.

There is always the option of just leaving the contaminants alone to decay, called natural attenuation. In such a case, monitoring is critical to ensure that the contaminants are not moving to areas where people are exposed.

\section{Recommendations}

- Independent agencies should be tracking the rates of cancerand other hea lth impacts a mong residents and on-site workers living near a site.

- Access to a contaminated site should be controlled to limit human health exposure and risk, especially at sites where contaminants are concentrated. 
- Risk assessment must be coupled with the selection of any technology for remediation.

\section{Companing Bioremediation to Other Technologies}

Considerable information exists about several altemative remediation technologies. Remediation technology selection requires information about site, geology, hydrology, levels of toxicity, and other factors. The following issues are directed towards the remediation of metals and radionuclides. Although each metal has its own toxic ity, all common metals and radionuc lide contaminants at DOE sites appear to be treatable by bioremediation.

\section{Issues}

Common technologies of dig-and-haul, solidification, and pump-and-treat can be considered to be effective, but have high cost.

The reduction of cost is an important issue to allow wide application of remediation technologies.

Regardless of the technology selected, metals and radionuclides cannot be degraded, but can be transfomed to reduce risk.

Technologies should be selected that minimize the movement of metal contaminated soils. The use of dig-and-haul creates an issue of increasing exposure to humans because it involves long tem storage and transportation.

Immobilization and isolation of metals and radionuclides in the ground is considered effec tive.

\section{Concems}

Even with successful immobilization, metals and radionuclides can be mobilized later in greater concentrations if bioremediation is stopped. Long-time maintenance of bioremediation is a concem.

If a technology proves to be either too expensive or of too long a duration, it will not be used and cleanup will not occur.

Long-time maintenance of bioremediation is a concem.

Altematives to bioremediation appear to be much more expensive and require transportation and deposition at altemative sites. This may lead to health issues and not-in-my-backyard opposition.

Bioremediation of metals and radionuclides may not be possible if organic compounds are also present. Therefore, physical or chemic al technologies may be required. 


\section{Recommendations}

- Every project must involve in-depth risk assessment in order to detemine appropriate technology.

- Where the geology is favorable, bioremediation should be used when metals or radionuclides a re underground in a bounded area.

- Diligent consideration should be given to use of bioremediation because of its positive attributes that a re responsive to public concems about risk, transportation, cost, effectiveness at a site, and human health.

- Continued research into bioremediation and other technologies is needed.

\section{Education and Outreach}

\section{Issues and Concems}

The information provided to the public on bioremediation needs to be more easily grasped or comprehensible by the citizen public. As community members who reside near a DOE site - - the Idaho National Engineering \& Environmental Laboratory - - we have observed more public relations related to contamination and cleanup issues at INEEL than public education. Issues and concems related to bioremediation can be difficult to obtain and understand. An adequate foundation for continuous leaming is not provided by current efforts. The public needs to be involved in cleanup decision-making and report writing.

\section{Recommendations}

- The consensus workshop is an excellent example of how citizens, interested in a complex issue, can leam and understand this topic. The panel members became engaged in seeking and gathering additional information for its decision-making.

- Education and outreach is a critical component of any public engagement and involvement effort. Education efforts must be separate from public relations efforts.

- The education materials should include a va riety of media, such as:

- Web information,

- Informational brochures,

- Newspaper, radio, or television information,

- Public meetings, and

- Other materials.

- People leam in different ways. The information must be balanced and fa ir and from knowable and unbiased sources. It needs to be readable and digestible for regular people. 
- Detailed studies lead to cleanup choices. The public needs a routine feedback loop to provide information about bioremediation cleanup and its progress and to solic it additional input. The public needs to be provided with understandable information about cleanup progress and, along with monitoring summaries, information about whether or not cleanup benchmarks are being a chieved. To be most useful to the public, monitoring data should be objectively gathered, summarized, and made comprehensible by a neutral party such as the US Geological Survey.

\section{Responsibility and Lability}

\section{Issues}

We disc ussed lia bilities and responsibilities for past practice conta mination issues. After hearing several presentations, we realize that the answers to these questions are site-specific. For example, at INEEL, the DOE is responsible for the contamination situation and the federal govemment is responsible for paying for the cleanup.

The public has a role in the process as well. The public is responsible for electing officials who hold the activities of the site as a prionity. Additionally, the public can improve the quality of decision-making processes by actively partic ipating in public involvement ac tivities.

\section{Recommendations}

- Like all remediation choices, if bioremediation is the chosen technology, then we have additional considerations about responsibility and liability. The Department of Energy (DOE) is responsible for long-term stewardship, and it is important to hold DOE accountable.

- Somebody has to oversee the DOE, and that is where a good oversight infrastructure is important to have in place. The roles of the contractor, state agencies, state offic es (the Govemor's office, for example), and federal agencies must be clear and the groups must be held accountable. Citizens groups should have access to pertinent information directly affecting the public.

- Insurance, endowments, and other financial mechanisms should be in place for unexpected outcomes of the chosen technology, including unexpected health effects or unexpected loss of funding.

- In Idaho, a state oversight process with state agency involvement and accountability to the Govemor has been passed into law. We recommend that a similar system of accountability directly to the Govemor be instituted at other sites. 


\section{Long Term Stewardship}

\section{Issues}

As citizens we are responsible for our planet and we a re concemed about future generations. Due to the long-term characteristics of metals a nd radionuclides at contaminated DOE sites, the slow movement of groundwater, the high complexity of the physical nature of the contamination, and the lack of continuous political will, long term plans and funding for monitoring contamination and cleanup must be in place.

\section{Concems}

Our concems include:

- Changing politic al c limate

- Multiplicity of agencies and laws involved in cleanup decisions at public ly owned sites

- Agency and oversight committee changes and tumover

- Legal and regulatory changes

- Diffic ulty in instituting long tem stewa rdship

- Determining what length of time we mean by "long term"

- Ability to meet the communities' vision of restoring the land for human use (not fencing the area off).

\section{Recommendations}

- We recommend a credible long-tem monitoring strategy for the contamination and the remediation be implemented. This also relates to providing accurate infomation and periodic reporting to the public and responsible agencies.

- A strategy needs to be in place to hold state and federal agencies responsible for long-tem stewardship. Legal mechanisms, including court-enforced orders, need to be in place to guarantee long-term stewardship.

- Stringent responsibilities should continue to be placed on contractors for meeting cleanup objectives, whether short- or long-term. The DOE should include aspects of long-term stewardship in their contracts, and the contracts should be enforced. This all depends on effective oversight.

\section{CONCLUSIONS}

In summary, bioremediation holds promise in being technologically and fiscally feasible under conditions where the site characteristics are appropriate. Ba sed upon the information provided, we believe that bioremediation is an effective way of treating conta minants. 
With respect to the cleanup of radionuclides and metals, issues that must be considered include public health, long-term stewardship, comparison of bioremediation to other technologies, public education, and the accountability of responsible parties. Continued research is needed in all these a reas.

As community members, our concems related to bioremediation as a remediation technology revolve around public and worker health issues. Due to the "forever" nature of heavy metals and radionuclides, continuing maintenance and the potential for altering exposure pathways concem us. We question the feasibility of guaranteeing long-tem stewardship extending hundreds of years.

We recommend comprehensive risk assessments, a nalysis of comparative cost effectiveness, and ongoing research should be applied to each site specific ally. These efforts need to be adequately funded. Continual public education and outreach, as well as public disclosure, should be a priority.

This consensus was reached through a citizen panel process, which we believe is an effective way to engage the public in decision making. Our panel process involved small and large group disc ussion, informative lectures, issue summaries, and consensus reports. We recommend that this panel process be used to establish a bridge between the public and decision-makers. This process is a good way to for the public to give opinions and recommendations to govemmental agencies. 


\section{Appendix A}

\section{Glossary of Tems and Acronyms Used in this Report}

Aquifer: A layer of water-saturated rock or soil through which water flows in a quantity useful to people.

Bioremediation: The use of microorganisms to degrade or transform hazardous organic contaminants or to transform hazardous inorganic contaminants to environmentally safe levels.

Contaminant Ha mful or haza rdous matter in the environment.

DOE: U.S. Department of Energy

Electron Acceptor: A small inorganic or organic chemical that is reduced in a metabolic oxidation-reduction reaction.

EPA: U.S. Environmental Protection Agency

Groundwater: Water found beneath the Earth's surface that fills pores between materials, such as sand, soil, or gravel; supplies wells and springs.

INEEL: Idaho National Engineering and Environmental Laboratory

Inorganic Chemicals: Chemicals that do not contain carbon, which is usually associated with life processes; for example, metals are inorganic.

Microbe or Microorganism: Any orga nism of mic rosc opic or ultra mic rosc opic size; in the context of bioremediation, the mic robes of interest typic ally a re bacteria.

Natural Attenuation: Degradation or transformation of conta minants that consists of the naturally occuming microbial populations and naturally occuming chemical, biological, and geological conditions. Also known as intrinsic bioremediation, bioattenuation, or passive bioremediation.

Organic Chemical: A chemical that contains carbon and hydrogen, elements usually associated with life processes.

Pump-and-treat A cleanup technology in which groundwater is removed, treated, and then retumed to the ground.

Radionuclide: A type of element that is unstable; it tries to stabilize itself by giving off radioactive particles. This process is called "spontaneous decay."

TAN: Test Area North 


\section{Appendix B}

Recruitment Ad

\section{Paid Leaming Opportunity!}

Would you like to partic ipate in research, conducted by Oregon State University, that looks at how to involve the public in decisions about cleanup technology?

This is an opportunity to leam about an actual hazardous substance cleanup technology, as well as participate in research to find better ways to involve the public in decisions about cleanup. Those selected to participate will leam about the technology of bioremediation in three weekend sessions, held in southem Idaho, on these dates:

- July 19-20, 2002 (Friday and Saturday)

- August 9-10, 2002 (Friday and Saturday)

- September 12-14, 2002 (Thursday, Friday, and Saturday)

If you wish to apply, you must be available to attend on all of these dates and be aged 18 or older. You must have no expert knowledge of or previous connection with bioremediation. Costs of car travel, lodging, and meals will be paid and each participant will receive a significant monetary stipend in one payment at the conclusion of the three sessions.

Are you interested? Write a brief letter (one page) describing yourself and why you would like to participate. Include your name, address, and telephone number. Mail to:

Stephanie Sanford, Project Manager

210 Strand Agric ulture Hall

Oregon State University

Corvallis, Oregon 97331

Telephone: 1-800-653-6110 or 541-737-5861

E-mail: stephanie.sanford@orst.edu.

Deadline for applic ations is May 17, 2002. 


\section{Appendix C}

\section{Panel Members and Project Staff}

\section{Panel Members}

Debi J ohnson

Jerome, Idaho

Dennis Lloyd

Idaho Falls, Idaho

Biffton Parks

Boise, Idaho

Tim Rhodes

Caldwell, Idaho

Robert Smith

Idaho Falls, Idaho
J ulie Knopp

Mackay, Idaho

Ka y Merriam

Pocatello, Idaho

Fran Peterson

Mounta in Home, Ida ho

Donald Robinson

Eden, Idaho

Sheri Thomson

Idaho Falls, Idaho

\section{Advisory Committee Members}

Janice Brown, Advisory Scientist, Ecologic al and Cultural Resources, Idaho National Engineering and Environmental Laboratory (INEEL)

P.O. Box 1625, Idaho Falls, ID 83415-2213

208-526-4342

E-mail: browjm@inel.gov

Gary Hickman, Senior Technolog ist, CH2M Hill

2300 NW Walnut Blvd, Corvallis, OR 97330

541-758-0235 x3521

E-mail: ghickman@ch2m.com

Lewis Semprini, Professor, Department of Civil, Construction, and Environmental Engineering, Oregon Sta te University

204C Memyfield Hall, Oregon State University, Corvallis, OR 97331

541-737-6895

E-mail: lewis.semprini@orst.edu

Kenneth Williamson, Professor and Head, Department of Civil, Construction, and Environmental Eng ineering, Oregon Sta te University

204 Apperson, Oregon State University, Corvallis, OR 97331

541-737-6836

E-mail: kenneth.williamson@orst.edu 


\section{Project Staff}

Denise Lach, Co-Director

Center for Water and Environmental Susta ina bility

210 Strand Agriculture Hall, Oregon State University

Corvallis, OR 97331

541-737-5471

E-mail: denise.lach@orst.edu

Stephanie Sanford, Program Coordinator

Center for Water and Environmental Susta ina bility

210 Strand Agric ulture Hall, Oregon State University

Corvallis, OR 97331

541-737-5861

E-mail: stephanie.sanford@orst.edu

Dorothy Tibbetts, Program Assistant, NABIR project

210 Strand Agric ulture Hall, Oregon State University

Corvallis, OR 97331

541-737-5861

E-mail: dorothy.tibbetts@orst.edu

\section{Facilitator}

J a net G illa sp ie, Environmental Strategies, LLC

537 SE Ash, Suite 12

Portland, OR 97214

503-233-3980

E-mail: janet@envirostrategies.com 


\title{
Appendix D
}

\section{Citizen Panel Charter \\ (Revised 7/ 19/02 and 7/20/02)}

\begin{abstract}
Mission
The mission of the consensus workshop citizen panel is to test a method of involving citizen interested citizen members in environmental remediation decision-making. This is a research project. It will test use of a new technique-a consensus workshop-as a method to involve the public in making environmental remediation decisions, with a focus on bioremediation techniques. The lay panel will leam as much information as possible about bioremediation to make good recommendations.

To make the research more valuable, a "place-based" problem-located at the Idaho National Engineering and Environmental Laboratory-will be used to explore various environmental issues associated with bioremediation.
\end{abstract}

This consensus workshop will not be directly involved in environmental remediation decisions at the INEEL

\section{Anticipated Schedule}

The schedule for the lay panel includes meetings near ldaho Falls as follows:

\begin{tabular}{|c|c|}
\hline Dates & Anticipated Meeting Schedule \\
\hline Friday, J uly 19 & Noon - 6 pm; short exerc ise after dinner \\
\hline Sa turday, J uly 20 & $8: 30 a m-3 p m$ \\
\hline Friday, August 9 & Noon - 6 pm; short exerc ise after dinner \\
\hline Saturday, August 10 & $8: 30 a m-3 p m$ \\
\hline Thursday, September 12 & Noon - 6 pm; short exerc ise after dinner \\
\hline Friday, September 13 & $8: 30 a m-6 p m$ \\
\hline Saturday, September 14 & $8: 30-3 p m$ \\
\hline
\end{tabular}

\section{Expected Outcomes}

The final expected outcome of the lay panel consensus workshop will be a written report documenting the panel's consensus on key questions and concems regarding bioremediation. The report will include the citizen panel's expectations, concems and recommendations. The recommendations should include bioremediation recommendations and recommendations regarding the use of this consensus workshop approach for securing public participation and involvement. 
Staff from Oregon State University will assist the citizen panel in developing the report and in production of the report, but the substance of the report will be written and directed by the citizen panel.

The citizen panel members will accept and personally endorse the written report with their signatures on the final copy.

Key milestones in developing the written report will be:

1. Inventory issues of panel concems regarding bioremediation environmental remediation tec hniques.

2. Leam adequate scientific information about bioremediation of environmental contamination issues to be able to describe them for the report.

3. With the information from milestones $\# 1$ and \#2, complete a list of technical questions that specific experts should address to the panel. The experts' qualific ations or other past work experience of interest to the panel should be included.

4. Reach consensus on questions, answers received, and recommendations regarding:

- Use of bioremediation techniques to treat legacy environmental pollution problems, and

- Use of a consensus citizen panel for citizen participation and input in to the remediation decision-making process.

5. Pull all the information into a single written report. Gain approval for the document from all citizen panel members. Signify approval by signing the report.

\section{Compensation}

Citizen panel members are devoting personal and professional time to participate in this process. An honorarium of $\$ 2,500$ will be awarded to each member that participates throughout the process at the conclusion of the process.

Automobile travel and per diem costs of citizen panel members will be paid by Oregon State University.

\section{Conduct}

To the extent possible, the group will attempt to reach consensus on the content of the report. Where not possible, minority reports may be developed. Consensus is defined as "you can live with it..."

A facilitator will be hired to assist the group in meeting organization and in reaching its goal of developing a final written report.

The group members will treat each other and the professional staff involved in the project with courtesy and respect. 


\section{Transparency}

The lay citizen panel has been selected to represent the community broadly. To encourage teamwork and frank discussion, members of the general public and the media will not be allowed to attend the working sessions of the citizen panel. If there is interest, the citizen panel may decide to set a specific time to hear from the public-either during the process or at the September workshop. A press release will be distributed to local media at the beginning and the end of the process. 


\section{Appendix E}

\section{Press Release}

\section{8-8-02 IDAHO RESIDENTS STUDYING BIOREMEDIATION}

By Stephanie Sanford, 541-737-5861 SOURCE: Denise Lach, 541-737-5471

CORVALLIS, Ore. - This summer 10 Southern Idaho residents are spending several weekends learning about bioremediation, in an innovative new approach to studying public perceptions about this promising technology for cleaning up environmental contamination.

Researchers at Oregon State University have asked 10 average citizens to learn about bioremediation - the use of bacteria to break down or change contaminants - and make recommendations for its use as a cleanup technology.

A “consensus workshop” technique is being used to teach the 10-person citizen panel about bioremediation. The panel will then develop questions about this technology, design the final meeting of the workshop so experts can help answer their questions, and produce a report that includes recommendations for the possible use of bioremediation at Department of Energy and other cleanup sites.

The research project is being conducted by Denise Lach and Kenneth Williamson at OSU, who are co-directors of the Center for Water and Environmental Sustainability, with a grant from the U.S. Department of Energy to study public perceptions of the use of bioremediation.

"We are pleased to partner with the Department of Energy on applying this public involvement technique to an important issue like bioremediation," said Denise Lach. "Selecting citizens from around the Southern Idaho area is a perfect way to test this concept. Bioremediation is a cleanup technique being used at the Idaho National Environmental and Engineering Laboratory, which is just one of a number of DOE sites where bioremediation cleanup techniques may be useful.”

According to Lach, this is one of the first uses of a consensus workshop to involve the public in decisions about hazardous waste cleanup. She and her colleagues hope to be able to show whether or not the consensus workshop is an effective outreach strategy that may be used by the Department of Energy in the future.

The Idaho residents who make up the panel come from Boise to Idaho Falls, Mackay and Twin Falls. The participants have agreed to spend a significant part of their summer learning about bioremediation and working with other panel members to write the consensus report. 


\section{Appendix F}

\section{Early Questions and Concerns}

We developed the first set of questions, which helped us identify the expertise we needed to hear from, during our first meeting in July. The questions can be organized into six different categories, each of which is described below.

\section{Bacteria}

- In the permit process for genetically modified organisms will the public be involved in decision-making?

- Are the bacteria being used pathogenic?

- When combining multiple bacteria with multiple chemicals (food), with multiple contaminants, what is the outcome along with the risk?

- When combining harmless substances will they cancel out or create a more toxic substance, etc.?

- What effects will radioactive material have on the introduced bacteria and chemicals?

- After the bacteria dies what is left? What happens?

- How is the growth and activities of the bacteria controlled?

\section{Chemicals}

- What contamination is best treated with bioremediation and why?

- What are the potential impacts/consequences of using bioremediation?

- What chemical mixtures might not be conducive to bioremediation?

- When is natural attenuation ("decay") a preferred approach? What basis?

- At what point can you use bioremediation if you have an active contaminant source?

\section{Geological}

- Where are the faults in the site a rea, and their directions?

- What are the flow rates of ground water at site?

- What is the leeching rate of the water from the surface to the groundwater?

- Are there historical data available for the site (e.g. well logs, soil tests, etc.)? What are the levels of contamination, sampling strategy, time line?

- Are all test wells dug to same depth? Or, do they go to the same stratigraphic la yer?

- What is being produced at labs (e.g. what are the waste streams)?

- What geologic research is going on? What is needed for bioremediation?

- Can we get a mixing rate that will work for the complex geology in combination with complex conta minants? 
- How is mobility of contaminant and/or treatment affected by the geology of the site?

- How does geology of site affect choice of cleanup technology?

- What about naturally-occuming metals/elements/stuff already in the ground/wa ter/air/vadose zone? How will bioremediation affect them?

- How will non-point pollution (e.g. fertilizers, phosphates, etc.) affect bioremediation effort?

- What are the conta mination rates across all aquifers?

- Will bioremediation process and/or residuals "clog" the a quifer?

\section{Technic al comparison}

- What other technologies are available to cleanup contamination?

- How does bioremediation compare to these technologies in terms of:

- effectiveness (i.e. how much it can clean up)

- how well it meets regulatory standards

- cost

- time

- safety

- risk of fa ilure

- what do we know-based on what evidence?

- existing/needed infrastructure (e.g., wells, pumps, roads, conta inment)

- public acceptability

- What are the safety issues related to bioremediation? The other technologies?

- How adaptable is bioremediation to advances in technology?

- How well do cleanup technologies work for various contaminants?

- How many bioremediation projects have moved beyond R\&D to full implementation? Provide descriptions:

- Where did it work?

- Where did it fail?

- Community acceptability in both

\section{Long-term stewardship}

- During and after bioremediation is complete, is the land useable for agric ulture, recreation, housing?

- Where, when, how, and who will be responsible for monitoring the sites?

- Where does the buck stop? Who has long-term legal liability?

- What monitoring is required and for how long?

- How much will it cost?

- Who will monitor and ma inta in it? - credibility, experience, biases

- How will weather become a factor? 


\section{Politics/communication}

- How do we currently engage the public and elected officials in bioremediation decisions? Describe stakeholders. In general, from state to state, who is responsible for conducting and overseeing the bioremediation process? What current laws/regulations a pply? What do agencies do and how many specialized employees does it take? Can existing agencies do the job?

- What can an agency do to limit the politicizing of the issues?

- Share examples and public response of how bioremediation has been applied here and elsewhere (e.g. Alaska, INEEL-TAN, and explosives).

- What means have other agencies used to communic ate details of their bioremediation efforts? How successful have they been? Lessons leamed?

- Who makescleanup decisions? 


\section{Appendix G}

\section{Technical and Scientific Presenters}

\section{Daniel Ackeman}

Dan Ackerman is a Hydrologist for the Department of the Interior, U. S. Geological Survey, Idaho District, Idaho National Engineering and Environmental Laboratory Project Office. He has a Batchelor of Science in Geology, Honors, University of North Dakota, Grand Forks, North Dakota and a Master of Science in Earth Sciences, University of Waterloo, Waterloo, Ontario. Dan has worked for more than 35 years as a technician, student, and as a professional in various capacities as geological scientist for the North Dakota State Geological Survey, University of Waterloo, and the U.S. Geological Survey. Since August 1988, Dan has worked as a staff specialist responsible for qua ntitative ground-water flowsystem characterization. Major projects and assignments with the $U$. S. Geological Survey include: county or basin-wide ground-water studies in North Dakota and Colorado; regional a quifer system assessments in various locations in the U.S.; oil shale geochemistry and hydrology studies, Colorado; fate and transport of contaminants by ground water, Idaho National Engineering and Environmental Laboratory, Idaho; water-quality discipline specialist, North Dakota District; and ground-water disc ipline specialist, Idaho District.

\section{Steve Anderson}

Steve Anderson received a BS in geology from the University of Arizona in 1976 and an MS in hydrology from the University of Arizona in 1978. He has worked for the US Geological Survey since 1978, specializing in ground-water hydrology and subsurface stratigraphy. Steve has spent the last 14 years studying the complex basalt stratigraphy underlying the eastem Snake River Plain at and near the Idaho National Engineering and Environmental Laboratory. Since 1996, he has been an affiliated faculty member of the Geology Department at Idaho State University.

\section{Janice Brown}

Janice Brown served on the advisory committee as an independent consultant. Professionally, she is an Advisory Scientist in the Department of Ecological and Cultural Resources, Idaho National Engineering and Environmental Laboratory (INEEL).

\section{Jonathon (J ack) Istok}

Jonathan (Jack) Istok is a professor of civil engineening at Oregon State University. He has taught and conducted research in conta minant hydrology for the last 22 years. For the last 6 years he has conducted research on the bioremediation of metals and radionuclides in groundwater at various DOE facilities a round the country. 


\section{Bob Nitschke}

Robert (Bob) Nitschke is presently a Fellow Scientist at the Idaho National Engineering and Environmental Laboratory. Bob's primary responsibility is the program and technical lead for the GY WORKS project which is a joint US Department of Transportation, US Department of Interior effort that applies systems analysis techniques to the relationships and impacts of energy, information, transportation and facility infrastructures in the greater Yellowstone region. Bob is also providing technical support to several major company initiatives including two research projects dealing with legacy risk issues and sustainable decision-making. Prior to this position Bob was the Manager of the Chemical and Radiological Risk Assessment Department in charge of conducting environmental risk assessments for the CERCLA program and performance assessments for the disposal of radioactive waste. He served on the DOE HQ Low-Level Radioactive Waste Peer Review Panel for five years. He has more than 28 years of management and technical experience in risk/performance assessment, safety analysis, environmental restoration, waste management, nuclear reactor operations/licensing, quality assurance and program management. Bob has a Master of Science degree in Nuclear Engineering and a Bachelor of Science degree in Physics from the Georgia Institute of Technology.

\section{Laird Noh}

Senator Laird Noh is the Idaho State Senator (R) representing District 23. He is a sheep producer from Kimbenly, Idaho who has served in the state legislature for over 20 years. Senator Noh currently chairs the Resources/Environment, Agric ultural Affairs, and Education Committees of the state legisla ture. He holds an M.B.A from the University of Chic ago.

\section{Kathy Peter}

Kathy Dyer Peter is the Chief of the Idaho District of the U.S. Geological Survey. Her experiences include: as State Representative for the USGS, serving as main point of contact for all USG S a ctivities in Idaho; District Chief, Oklahoma District; Chief Hydrologic Investigations, New Mexico District; Hydrologist, South Dakota and Wyoming Districts; participation as member of several interagency statewide water resources advisory groups, such as the Oklahoma Water Quality Monitoring Council and the Illinois River Task Force; chaining Division-level committees, such as the Computer Policy Advisory Committee and the Financial Work Group for the Division Administrative Information System; member of the Extemal Advisory Board to the Oklahoma Center for Toxicology; chair of the Oklahoma Federal Executive Board in FY99. She eamed a B.S. in Geological Sc iences from Pennsylvania State University and a M.S. in Geological Engineering from South Dakota School of Mines and Technology and is a registered Professional Engineer in South Dakota. After joining the Survey in 1974 as a hydrologist, her research has primarily been on ground water and water quality in Wyoming, South Dakota, and New Mexico. Kathy is mamied to Fred S. Peter, $\mathrm{J} r$. and they have two sons, Keith and Christopher. 


\section{Lance Peterson}

Lance is Vice President of the Remediation Technologies Division of North Wind Environmental. He has an ABD, Ph.D. in Chemistry and a BA in Chemistry. Lance has 29 years experience in environmental remediation, specializing in chlorinated solvent remediation; trichloroethylene-contaminated, deep fractured basalt aquifer cleanup, and bioremediation.

\section{Kathleen Trever}

Kathleen Trever has experience and educational background in a variety of technical, legal and policy fields. She currently serves as the State of Idaho's Coordinator for INEEL Oversight. In this capacity, she advises Govemor Kempthome on policy matters related to the INEEL and other U.S. Department of Energy activities and heads the state's INEEL Oversight Program. The Oversight Program independently monitors DOE activities on behalf of ldaho citizens. Kathleen also works with representatives from other states housing DOE facilities in regional and national forums to address problems surrounding the safe management of the nation's nuclear materials. Kathleen formerly served as a Deputy Attomey General for the State of Idaho in the Natural Resources Division. She handled cases related to DOE activities in Idaho and pollution from historic mining activities. Kathleen tumed to the legal profession after working as an exploration geologist for mining companies in Nevada, Utah and Montana. She has a Bachelor's Degree in Geology from Harvard University and a Law Degree from Lewis and Clark Northwestem School of Law. Kathleen grew up on Maryland's Eastem Shore.

\section{Kenneth Williamson}

Ken Williamson is Professor and Head of the Department of Civil, Construction, and Environmental Engineering at Oregon State University. He also serves as Asso cia te Director of the Westem Region Hazardous Substance Research Center and Director of the Technical Outreach Services for Communities and Technical Assistance to Brownfields Communities. With Dr. Denise Lach, Ken co-chairs the Center for Water and Environmental Susta ina bility. Ken's a reas of specia lization include: biological and chemical waste treatment; environmental impact assessment; haza rdous waste treatment and management; bioremediation; and technology transfer and technical outreach. Ken has B.S. and M.S. degrees in Engineering from Oregon State University and a Ph.D. in Environmental Engineering from Stanford University. 


\section{Appendix $\mathrm{H}$}

\section{Presentations}

The citizen panel heard the following presentations at the July, August, and September consensus workshops.

1. Basic s of Bioremediation Science* Ken Williamson, Oregon State University

2. INEEL Site: Historic al Summa ry J an Brown, INEEL

3. Geology and Hydrogeology of INEEL Site* Dan Ackerman, US Geological Survey

4. Bioremediation Projects Underway at INEEL Lance Peterson, North Wind Environmental

5. Policy Options for Long Term Stewardship Kathleen Trever, Idaho DEQ

6. Bioremediation of Radioac tive Conta minants and Metals* Dr. J onathan Istok, Oregon State University

7. Public Health and Risk Assessment Approaches*

Bob Nitsc hke, INEEL

8. Cleanup Techniques - A Comparison* Ken Williamson, Oregon State University

9. A State's Option for Sec uring Long Term Steward ship Laird Noh, Idaho Senator

"Slides for the following presentations are a va ilable on the project website at http://www.cwest.orst.edu/nabir/index.htm 